NBER WORKING PAPER SERIES

\title{
MODEL UNCERTAINTY AND LIQUIDITY
}

\author{
Bryan R. Routledge \\ Stanley E. Zin \\ Working Paper 8683 \\ http://www.nber.org/papers/w8683
NATIONAL BUREAU OF ECONOMIC RESEARCH
1050 Massachusetts Avenue
Cambridge, MA 02138
December 2001

We thank Burton Hollifield, Erzo Luttmer, David Marshall, and seminar participants at Boston College, CalTech, Carnegie Mellon, the International Monetary Fund, Tulane, CEF-2000 (Barcelona), the Econometric Society World Congress (Seattle), and the NBER Summer Institute for helpful comments. The views expressed herein are those of the authors and not necessarily those of the National Bureau of Economic Research.

(C) 2001 by Bryan R. Routledge and Stanley E. Zin. All rights reserved. Short sections of text, not to exceed two paragraphs, may be quoted without explicit permission provided that full credit, including $(\mathrm{C}$ notice, is given to the source. 
Model Uncertainty and Liquidity

Bryan R. Routledge and Stanley E. Zin

NBER Working Paper No. 8683

December 2001

JEL No. G10, G13, G20

\begin{abstract}
Extreme market outcomes are often followed by a lack of liquidity and a lack of trade. This market collapse seems particularly acute for markets where traders rely heavily on a specific empirical model such as in derivative markets. Asset pricing and trading, in these cases, are intrinsically model dependent. Moreover, the observed behavior of traders and institutions that places a large emphasis on "worst-case scenarios" through the use of "stress testing" and "value-at-risk" seems different than Savage rationality (expected utility) would suggest. In this paper we capture model-uncertainty explicitly using an Epstein-Wang (1994) uncertainty-averse utility function with an ambiguous underlying asset-returns distribution. To explore the connection of uncertainty with liquidity, we specify a simple market where a monopolist financial intermediary makes a market for a propriety derivative security. The market-maker chooses bid and ask prices for the derivative, then, conditional on trade in this market, chooses an optimal portfolio and consumption. We explore how uncertainty can increase the bid-ask spread and, hence, reduces liquidity. In addition, "hedge portfolios" for the market-maker, an important component to understanding spreads, can look very different from those implied by a model without Knightian uncertainty. Our infinite-horizon example produces short, dramatic decreases in liquidity even though the underlying environment is stationary.
\end{abstract}

Bryan R. Routledge

GSIA, Carnegie Mellon University

Pittsburgh, PA 15213-3890

rout@sulawesi.gsia.cmu.edu
Stanley E. Zin

GSIA, Carnegie Mellon University

Pittsburgh, PA 15213-3890

and NBER

zin@cmu.edu 


\section{Introduction}

In August 1998 an odd thing happened: the Russian government repudiated debt. While this event had a large effect on the value of Russian bonds, the event, by itself, is not odd. Long prior to August, yields on Russian government bonds exhibited a significant premium over comparable U.S. Treasury securities, suggesting that default (or at least rescheduling) was not only possible but carried non-trivial probability. These bonds were undoubtedly ex ante risky. The ex post default and the change in the bond's price can be viewed simply as a realization from the distribution of possible payoffs (i.e., "risk happens"). What is truly odd about the Russian-debt default, and the subsequent collapse of the prominent hedge-fund Long Term Capital Management, was that during the crisis, markets for most emerging-markets debt exhibited a severe lack of liquidity. Bid-ask spreads on emerging market debt increased from 10-20 basis points to $60-80$ basis points following the crisis. ${ }^{1}$ More dramatically, a number of market-makers withdrew from trading and did not post quotations while others reported that the market became "one-sided." 2 The lack of liquidity was not limited to the Russian debt market and emerging market bonds. The "flight-to-quality" made trading in corporate debt difficult as bid-ask spreads increased dramatically. ${ }^{3}$ In addition, several initial public offerings, including that of Goldman Sachs, as well as several corporate bond offerings and were canceled, reportedly, due to a lack of liquidity. ${ }^{4}$

The extremely large change in financial prices, in particular the credit spreads, observed over this period had little, if any, historical precedent. My-

\footnotetext{
${ }^{1}$ See International Monetary Fund (1998).

${ }^{2}$ See Bank of International Settlements (1999) report which surveyed market participants following the crisis. The Wall Street Journal reported on November 16th, 1998, (page A1) that "LTCM's partners... reported that their markets had dried up. There were no buyers, no sellers. It was all but impossible to maneuver out of large trading bets."

${ }^{3}$ Bank of International Settlements (1999) reports that bid-ask spreads for U.K. AA corporate bonds doubled and U.K. BAA bonds tripled.

${ }^{4}$ On October 7th, The Wall Street Journal reported (page A1) on liquidity in the corporate bond market: "According to [Scott's Fertilizer Company's] lead investment bankers at Salomon Smith Barney, there is no bond market at any price."
} 
ron Scholes, a partner in Long-Term Capital Management (LTCM) at the time of the Russian debt crisis noted the improbability of the events of August 1998. One week after the Russian government default, the swap credit spread increased 20 basis points (treasury bond yields versus AA rated debt yields). The increase is ten standard deviations above historic norms. ${ }^{5}$ The large and dramatic change in financial prices was not the only source of uncertainty. There was uncertainty about the solvency of some U.S.-based financial institutions. The Federal Reserve Bank's role in facilitating a recapitalization of LTCM, a hedge fund, was unprecidented. More generally, there was uncertainty about the Federal Reserve Bank's interest rate policy. The subsequent rate cut on October 15, 1998, represented a change from inflation targeting. ${ }^{6}$

Many economic models can incorporate unusual events like the Russian crisis as rare events, structural breaks, or changes in the risk premiums. From any of these perspectives, standard models would typically predict a capital loss by some, a capital gain by others, and perhaps a change in the marketprice process. However, most models are unable to explain the drop in liquidity that accompanies the crisis. ${ }^{7}$ The puzzle is not the large change in financial prices, it is that people seem to stop trading. In this paper we investigate the connection between uncertainty and liquidity.

The Russian debt crisis and market collapse is not unique. For example, Summers (2000) recounts the five other major international financial crises that took place during the 1990's involving economies in Mexico, Thailand, Indonesia, South Korea, and Brazil. Domestically, there have been many market collapses or crashes including the 1975 municipal bond crisis sparked by

\footnotetext{
${ }^{5}$ See Scholes (2000). Note that for a normal distribution, the probability of a 10 standard deviation tail event is on the order of $10^{-24}$ which is roughly the likelihood of winning the Powerball lottery three times in a row. It was also rumored at the time, that relative to some of LTCM's empirical models, price changes of this magnitude represented a 23 standard deviation event. The likelihood for a normal distribution of such an observation is on the order of $10^{-117}$ (for comparison, the number of atoms in the universe is on the order of $\left.10^{78}\right)$.

${ }^{6}$ See Marshall (2001).

${ }^{7}$ Marshall (2001) models a liquidity crisis as a "bad" equilibrium in coordination a game of asymmetrically informed lenders and borrowers.
} 
New York City's near default, various stock market crashes $(1929,1987,1989)$, and the collapse of the high-yield debt market in the early 1990's. While all of these events have their unique aspects, they share two common features. First, times of crises are associated with a greater degree of uncertainty. Almost by definition, a crisis involves a substantial change in financial prices so the ex ante likelihood of the event is low and the event is unusual. However, as in the case of the Russian crisis, there is an increased degree of uncertainty. For example, Prati and Sbracia (2001) documents that the dispersion in forecasts of economic growth increased during the Asian financial crisis. Second, crises are accompanied by a severe lack of liquidity. Following the various recent international and domestic crises, liquidity disappeared. Bid-ask spreads increase, ${ }^{8}$ people have difficulty executing trades for existing financial securities, and new bond and equity offerings are postponed or canceled. In this paper we investigate the connection between these two features. We investigate whether severe reduction in liquidity, or a "market break" can result from "model uncertainty." In particular, we focus on markets such as financial derivatives in which traders must rely on an empirical model for the stochastic cash-flow process of an underlying security. This is a setting where asset pricing and trading is intrinsically model-dependent. By specifying preferences that explicitly incorporate "model uncertainty" in a simple market-making setting, we show how uncertainty and liquidity are related.

To study the uncertainty-liquidity connection, we focus on a financial intermediary. The role of an intermediary is to facilitate trade. In well-developed liquid markets, the role of an intermediary is the straightforward matching of buyers and sellers (e.g., the specialist at the NYSE). In contrast, in more specialized financial markets like "proprietary products," the intermediary participates directly in the transaction. For example, according to Scholes (2000), LTCM was in the "business of supplying liquidity." This type of intermediation requires an ability to value and hedge the financial contract that is being provided. Typically, firms attack this problem in two disjoint approaches.

\footnotetext{
${ }^{8}$ Becker, Chadha, and Sy (2000) document the increase in bid-ask spreads in foreign exchange and interbank rates following the 1997-1998 Asian crisis.
} 
They use a model like Black and Scholes (1973) to calculate arbitrage bounds and hedge trades for a financial contract. However since the financial model is only an abstraction that is based on limited data, firms typically "stress test" their model to account for "model risk." For example, "Value at Risk" calculates the loss potential over a specified horizon for an arbitrarily specified probability. A portfolio resulting from the sale of a financial contract and an offsetting (perhaps dynamic) hedge position might have a $1 \%$ likelihood of losing $\$ 50$ million over the next two weeks. Exactly how large a tail to measure and what distributional assumption to make are left to judgment. What is striking about the amount of attention paid to worst-case scenarios, stress testing and value-at-risk calculations is that trader attitudes towards uncertainty of the correctness of their model is distinct from the risk of stochastic prices. That is, the preferences expressed by this behavior do not adhere to the Savage (1954) axioms for expected utility rationality.

Savage rationality, in particular the independence or sure-thing axiom, implies that preferences should not depend on the source of the risk. Uncertainty about the appropriateness of a pricing model, "model uncertainty," is indistinguishable from the risk inherent in the assumed stochastic process. The Savage independence axiom implies that one can simply collapse the probability weighting across possible models ("uncertainty") with the probabilities for payoffs ("risk") to represent behavior with a single probability measure for states. However, in experimental settings, decision makers consistently violate the independence axiom. For example, Ellsberg (1961), demonstrated that individuals' decisions over lotteries could not be represented by an expected utility decision rule. People expressed (revealed) a preference to "know the odds" or an aversion to uncertainty. In the context of financial intermediation, not knowing the realization of an asset payoff (consumption risk) and not knowing the probability measure for payoffs (model uncertainty) have different behavioral implications. This distinction between risk and uncertainty, first described by Knight (1921), is axiomatized in Gilboa and Schmeidler (1989). The resulting decision rule that captures uncertainty aversion is represented by Choquet (1955) utility. Given a random variable $\omega \in \Omega$, an agent chooses 
the optimal action, $\theta \in \Theta$, according to

$$
\max _{\theta \in \Theta}\left\{\min _{\pi \in \Pi} E_{\pi}[u(\theta, \omega)]\right\}
$$

Uncertainty is captured by the set of probability measures $\Pi$. The aversion to uncertainty manifests itself in the "min" operator that appears after the action is chosen. If the set $\Pi$ is a singleton, then the decision rule is the standard Savage rationality of expected utility. ${ }^{9}$ In this paper, we use the recursive intertemporal formulation of uncertainty aversion of Epstein and Wang (1994) and (1995). This specification facilitates dynamic programming and preserves dynamic consistency. ${ }^{10}$ The robust control framework of Hansen, Sargent, and Tallarini (1999) is similar to the Epstein and Wang approach. In a linearquadratic model the mean return, for example, is chosen by a malevolent nature. The result is the same "min" operator as in Choquet utility.

Our goal in the paper is to understand the relationship between model uncertainty and liquidity. The Choquet representation of uncertainty aversion is well defined. However, at any level of generality, "liquidity" is difficult to define. Analogous to the vacuous distinction between unemployment and leisure in a perfect labor market, parties choosing not to trade in a frictionless financial market is not a lack of liquidity. Liquidity can only be defined relative to a market friction. Models of liquidity must include a market friction like an imperfectly competitive market or asymmetric information. Within the context of some market imperfection, liquidity is commonly measured as a "discount for immediacy" (e.g. Grossman and Miller (1988)) or the "price impact of a trade" (e.g. Kyle (1985)). In this paper we wish to study the relationship between liquidity and uncertainty rather than market microstructure per se. We, therefore, specify a rather simple market mechanism. We focus on the bid

\footnotetext{
${ }^{9}$ A closely related approach of Gilboa (1987) and Schmeidler (1989) models subjective prior beliefs to be non-additive. In a coin toss, uncertainty aversion is captured by $P($ head $)+$ $P($ tail $)<1$.

${ }^{10}$ Time inconsistent examples with uncertainty aversion is a concern since there is no restriction that conditional events have less uncertainty than unconditional. Seidenfeld and Wasserman (1993) define and provide examples of this dilation of beliefs.
} 
and ask prices for a proprietary derivative security. The market-maker for this derivative is assumed to be a monopolist in that market while the market for the underlying security is frictionless. We therefore treat the bid-ask spread and the associated probability that the market maker will make a trade, as a measure of liquidity in the market for this derivative security. ${ }^{11}$

Specifically, we consider a financial intermediary who makes a market for a propriety derivative security. This market maker chooses bid and ask prices for the derivative to optimally tradeoff the probability of attracting a seller or buyer with the current income and future utility implications implied from a trade in the derivative. When there is ambiguity about the appropriate probability distribution for the underlying security's cash flows, the marketmaker is uncertain about these dynamic consequences, which we model with an Epstein-Wang uncertainty-averse utility function. We find that uncertainty increases the bid-ask spread and, hence, reduces liquidity. In addition, "hedge portfolios" for the market maker can look very different from those implied by a model without Knightian uncertainty.

In Section 2, we lay out the basic economic environment and describe the market-makers problem. In Section 3, we explore some simple two-period examples of the general model and in Section 4 extend these examples to an infinite time horizon. Section 5 concludes the paper.

\section{The Model}

The model we consider is that of a monopolist making a market in a derivative asset as well as choosing optimal portfolio and consumption. The marketmaker sets a bid and ask price for a derivative whose payoff is $X\left(P_{t}\right) \geq 0 .{ }^{12}$

\footnotetext{
${ }^{11}$ The setting we adopt here is similar to Ho and Stoll (1981) and related inventory-based microstructure models.

${ }^{12}$ In order to maintain the intuitive bid-ask relation, $0<b<a$, we will only consider derivatives with non-negative payoffs.
} 
Trades by the market maker are discrete short, no-trade, or long events, denoted $d_{t} \in\{-1,0,1\}$. The "size" of a trade can be incorporated into the definition of the derivative's payoff. For concreteness, our numerical examples focus on the case of a one-period call option $X\left(P_{t}\right)=s \max \left(P_{t}-x, 0\right)$. The parameter $s$ determines the size or importance of each trade.

The demand for the derivative is summarized by the arrival of a random willingness-to-trade $\tilde{v}_{t}$. If $\tilde{v}_{t}$ is greater than or equal to the posted ask price, $a_{t}$, then a "buy order" is received and the market maker must go short one call (denoted as $d_{t}=-1$ ), at a price of $a_{t}$. If the willingness-to-trade $\tilde{v}_{t}$ is less than or equal to the posted bid price, $b_{t}$, then the market maker must go long one call $\left(d_{t}=1\right)$, at a price of $b_{t}$. If $\tilde{v}_{t}$ lies between the bid and ask prices, no trade takes place $\left(d_{t}=0\right)$. We assume the willingness to trade is an i.i.d. process with $\Phi(v)=\operatorname{Prob}(\tilde{v}<v)$. The bid and ask prices determine the likelihood of trade in the derivative with $\operatorname{Prob}\left(d_{t}=-1\right)=\left[1-\Phi\left(a_{t}\right)\right]$, $\operatorname{Prob}\left(d_{t}=0\right)=\left[\Phi\left(a_{t}\right)-\Phi\left(b_{t}\right)\right]$, and, $\operatorname{Prob}\left(d_{t}=1\right)=\Phi\left(b_{t}\right)$. For simplicity, we assume $\Phi(v)$ is atomless and define $\phi(v)=\partial \Phi(v) / \partial v$.

The exogenous random arrival of a trade request is consistent with a number of deeper microstructure models. This simple specification of the market structure for the derivative lets us focus on the effect of return-uncertainty on liquidity. Note that there is no uncertainty about the distribution governing trade arrival. To explore uncertainty about the market microstructure itself, a more detailed specification of the market would be needed.

After the arrival of the request to trade, the market maker chooses an optimal consumption and investment in a risky asset. This allows the market maker the opportunity to dynamically hedge the realized position in the derivative market. 


\section{$2.1 \quad$ Investment Opportunities:}

We denote as $\theta_{t-1}$ the asset holdings brought into period $t, \theta_{t}$ the assets purchased in period $t$ to be carried into $t+1, P_{t}$ as the ex-dividend price of the underlying risky asset, and $\delta_{t}$ as the period- $t$ dividend paid by the risky asset. ${ }^{13}$ The market for the underlying asset is assumed to be frictionless. $c_{t}$ is period- $t$ consumption and $\omega_{t}$ is the income of the market-maker in period $t$. The period- $t$ budget constraint is:

$$
\theta_{t-1}\left(P_{t}+\delta_{t}\right)+\omega\left(y_{t}, v_{t}, d_{t-1} ; a_{t}, b_{t}\right)=c_{t}+\theta_{t} P_{t}
$$

Total income, $\omega\left(y_{t}, v_{t}, d_{t-1} ; a_{t}, b_{t}\right)$, includes both exogenous income and derivatives trading income. Exogenous period $t$ income is denoted $y_{t}$. The market-making activity affects income both through the derivative position, $d_{t-1}$, carried into period $t$ and through new trades in the derivative. The trading income in the current period depends on the choice of ask, $a_{t}$, and bid, $b_{t}$, and the realization of the willingness-to-trade, $\tilde{v}_{t}$.

$$
\omega\left(y_{t}, v_{t}, d_{t-1} ; a_{t}, b_{t}\right)=y_{t}+d_{t-1} X\left(P_{t}\right)+\left\{\begin{aligned}
a, & \text { if } v_{t} \geq a_{t} \\
0, & \text { if } b_{t}<v_{t}<a_{t} \\
-b, & \text { if } v_{t} \leq b_{t}
\end{aligned}\right.
$$

The trading outcome also determines the position in the derivative $d_{t}$ the market maker will carry forward into the next period. That is $d_{t}=-1$ if $v_{t} \geq a_{t}, d_{t}=0$ if $b_{t}<v_{t}<a_{t}$, or $d_{t}=1$ if $v_{t} \leq b_{t}$.

The timing of events implied by this notation is shown in Figure 1. The market maker enters period $t$ with holdings in the underlying security of $\theta_{t-1}$ which pay a dividend of $\delta_{t}$ and are liquidated at the price $P_{t}$. Holdings in the derivative of $d_{t-1}$ have cash-flows realized of $X\left(P_{t}\right)$. Finally, he collects

\footnotetext{
${ }^{13}$ The dividend on the risky asset is helpful in constructing the simple numerical example in Section 4. It is not needed for any of the analytical discussion or the two period example in Section 3.
} 
Figure 1: Model Time-Line

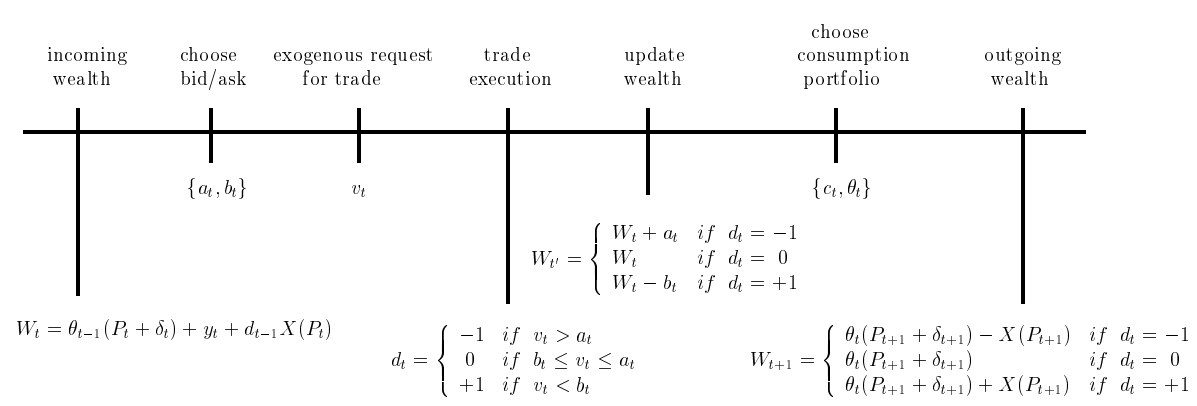

exogenous income of $y_{t}$. Given this information, he chooses a bid price, $b_{t}$, and an ask price, $a_{t}$. After the bid and ask are set, the exogenous request for a trade arrives, i.e., $\tilde{v}_{t}$ is realized. Knowing the outcome of the trade in the derivative market, the market maker then chooses date $t$ consumption, $c_{t}$, and investment in underlying risky security, $\theta_{t}$.

\subsection{Preferences:}

The stochastic process governing the transition of the underlying security price and exogenous income is assumed to be Markov, with transition density given by

$$
\operatorname{Prob}\left\{P^{\prime}, \delta^{\prime}, y^{\prime} \mid P, \delta, y\right\}=\pi(P, \delta, y)
$$

If the market maker has uncertainty or ambiguity about these probabilities, we will denote as $\Pi$ the set of all such distributions. As in Epstein and Wang (1995), we assume that this set is time invariant. It should be thought of as part of the investor's preferences, rather than the physical environment since the uncertainty is only relevant if the agent's preferences are averse to ambiguity. Also following Epstein and Wang, we assume that preferences are 
given by the utility function, $U$, that is the stationary, recursive specification of uncertainty aversion:

$$
U\left(c_{0}, \tilde{c}_{1}, \tilde{c}_{2}, \ldots\right)=u\left(c_{0}\right)+\beta \min _{\pi \in \Pi} E_{\pi} U\left(\tilde{c}_{1}, \tilde{c}_{2}, \ldots\right)
$$

where $0<\beta<1$ is a utility discount factor and $u(c)$ is the single period utility derived from consumption $c$. Standard Savage preferences are included in this specification. If the set $\Pi$ as a singleton, the agent adheres to Savage axioms.

\subsection{Bellman Equation:}

Combining the investment opportunity, the consumption implied by the budget constraint (2), and the specification of preferences, we can characterize this problem as a dynamic program. The Bellman equation associated with this program is given by:

$$
\begin{array}{r}
V(\theta, d, P, \delta, y)=\max _{a, b}\left\{[ 1 - \Phi ( a ) ] \left\{\operatorname { m a x } _ { \theta ^ { \prime } } \left[u\left(\theta(P+\delta)+y+d X(P)+a-\theta^{\prime} P\right)\right.\right.\right. \\
\left.\left.+\beta \min _{\pi \in \Pi} E_{\pi}\left[V\left(\theta^{\prime},-1, P^{\prime}, \delta^{\prime}, y^{\prime}\right)\right]\right\}\right\} \\
+[\Phi(a)-\Phi(b)]\left\{\operatorname { m a x } _ { \theta ^ { \prime } } \left[u\left(\theta(P+\delta)+y+d X(P)-\theta^{\prime} P\right)\right.\right. \\
\left.\left.+\beta \min _{\pi \in \Pi} E_{\pi}\left[V\left(\theta^{\prime}, 0, P^{\prime}, \delta^{\prime}, y^{\prime}\right)\right]\right]\right\} \\
+\Phi(b)\left\{\operatorname { m a x } _ { \theta ^ { \prime } } \left[u\left(\theta(P+\delta)+y+d X(P)-b-\theta^{\prime} P\right)\right.\right. \\
\left.\left.\left.+\beta \min _{\pi \in \Pi} E_{\pi}\left[V\left(\theta^{\prime}, 1, P^{\prime}, \delta^{\prime}, y^{\prime}\right)\right]\right]\right\}\right\} .
\end{array}
$$

$V(\theta, d, P, \delta, y)$ is the value function. It depends on the five state variables: the position in the asset, the position in the derivative, the realized price for the asset, the realized dividend, and the realization for the exogenous income. The portfolio (and hence consumption), are chosen after the realization of $\tilde{v}$, which along with $a$ and $b$, determines the outgoing position in the derivative. The outgoing position in the derivative, $d^{\prime}$, characterizes the future effect from 
the derivative trading (i.e., $a, b, \tilde{v}$ need not be included in the list of state variables).

Although closed-form solutions for the optimal policies of this dynamic program are unavailable, there are many computational algorithms that can be used to solve numerical versions of this model. When the set $\Pi$ is not a singleton, the computational burden associated with solving this problem can be significantly greater than in the standard expected utility model. The additional non-linear program necessitated by the uncertainty averse preferences (minimizing over distributions) increases computation time. Routledge, Trick, and Zin (2000) offer some new approaches to this problem that may yield significant computational gains.

\section{Two-Period Model}

To better understand the connection between uncertainty and liquidity, we first examine a simpler, two-period $(t=0,1)$ version of the economy. Here, the market maker makes a market in a derivative of the single risky asset at period zero and the derivative payoffs at period one. The single risky asset, whose prices are $P_{0}$ and $P_{1}$, trades in a perfect market. In this section, the dividend is zero, $\delta_{0}=\delta_{1}=0$, and exogenous income, $y_{0}$ and $y_{1}$ are nonstochastic.

\subsection{Portfolio Choice with Uncertainty Aversion}

Since the portfolio is chosen after the realization of trade in the derivative, we can consider the portfolio choice and the market-making activity separately. To do this, write the Bellman equation in two parts. The full market-maker problem is discussed in Section 3.2. However, before characterizing the optimal period zero bid and ask prices, we first consider the choice of the optimal 
consumption and portfolio. How Knightian uncertainty affects the optimal portfolio turns out to be very important to understanding the market-making problem.

The portfolio problem is the inner maximization over $\theta^{\prime}$ in equation (6). Note that a portfolio choice determines consumption via the budget constraint. That is, $c_{0}=\omega_{0}-\theta P_{0}$ and $c_{1}=\omega_{1}+\theta P_{1}$. Define the indirect total utility function $U(d, a, b)$ as follows:

$$
U(d, a, b)=\max _{\theta}\left\{u\left(\omega_{0}-\theta P_{0}\right)+\beta \min _{\pi \in \Pi} E_{\pi}\left[u\left(\omega_{1}+\theta P_{1}\right)\right]\right\}
$$

The two-period version of income, equation (3), is

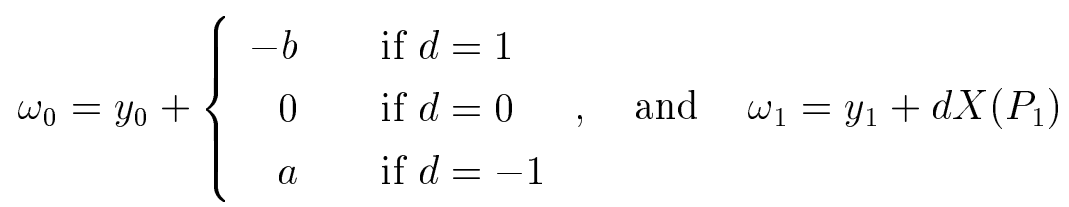

Since $U(d, a, b)$ is conditional on the realization for the trade in the derivative market, the ask and bid prices have implications only for period-zero income. Therefore, $U(d, a, b)$ does not depend on $a$ or $b$ if $d=0$. Similarly, it does not depend on ask price, $a$, if a "buy" order occurred and $d=1$. Finally, $U$ does not depend on the bid price $b$ if a "sell" order $d=-1$ was received. Therefore, we can summarize equation (7) with three functions. Denote $U_{0}$ when there is no trade in the derivative $(d=0), U_{b}$ when the market maker has paid $b$ and is long the derivative $(d=1)$, and $U_{a}$ for when the market maker sold the derivative for $a$ and holds a short position $(d=-1)$.

For concreteness, consider the portfolio choice for three different agents $i \in\{1,2, K\}$. Two Savage individuals are captured with $\Pi^{1}=\left\{\pi^{1}\right\}$ and $\Pi^{2}=$ $\left\{\pi^{2}\right\}$. An individual with an aversion to Knightian uncertainty is represented by $\Pi^{K}=\left\{\pi^{1}, \pi^{2}\right\}$. Obviously, to make this example interesting, $\pi^{1} \neq \pi^{2}$.

For Savage individuals $i=1,2$, the optimal portfolio is characterized by 
the standard first order condition.

$$
-u^{\prime}\left(w_{0}-\theta^{i} P_{0}\right) P_{0}+\beta E_{\pi^{i}}\left[u^{\prime}\left(w_{1}+\theta^{i} P_{1}\right) P_{1}\right]=0
$$

Figures 2 and 3 plot total utility (right-hand-side of (7)) against portfolio holdings, $\theta$, given income and prices. The utility is plotted for each distribution $\pi^{1}$ and $\pi^{2}$ and the Savage-optimal portfolios, $\theta^{1}$ and $\theta^{2}$, are indicated. For exposition, the utility function is quadratic and the distribution, $\pi^{i}$, is summarized by its mean and variance.

The Knight agent's utility in Figures 2 and 3 is the lower envelope of the two Savage agents. There are two possibilities for how the optimal portfolio of the Knight individual is characterized. First, the aversion to uncertainty can make the Knight agent act according to the worst-case probability distribution. Here, the Knight agent simply looks like a pessimistic or "worst-case" Savage agent. Distribution $\pi^{1}$ is the worst-case near $\theta^{1}$ in Figure 2 since $E_{\pi^{1}}\left[u\left(\omega_{1}+\theta^{1} P_{1}\right)\right]<E_{\pi^{2}}\left[u\left(\omega_{1}+\theta^{1} P_{1}\right)\right] .{ }^{14}$ In this case, $\theta^{K}=\theta^{1}$ and the optimal portfolio satisfies the first-order condition in equation (9). The definition of worst-case depends on the correlation between period-one income and the asset payoff. Since, as we will explore below, market-making activity influences this correlation, the distribution that is considered as worst-case may depend on the market-maker's position in the derivative.

The definition of the worst-case distribution will also depend on the portfolio. In Figure 2 very large long or short positions in the asset switch the characterization of worst-case to $\pi^{2}$ (note that $\pi^{2}$ has a larger variance than $\pi^{1}$ ). However, for portfolios in the neighborhood of $\theta^{K}$ (which is equal to $\theta^{1}$ ), distribution $\pi^{1}$ is always the worst-case. In contrast, Figure 3 is an example where, at the optimal Knight portfolio, there is no portfolio-free characterization of the worst-case. This is the second possibility for the characterization

\footnotetext{
${ }^{14}$ This condition implies that $E_{\pi^{2}}\left[u\left(\omega_{1}+\theta^{2} P_{1}\right)\right]>E_{\pi^{1}}\left[u\left(\omega_{1}+\theta^{2} P_{1}\right)\right]$.
} 
Figure 2: Optimal Portfolio: Quadratic Example 1

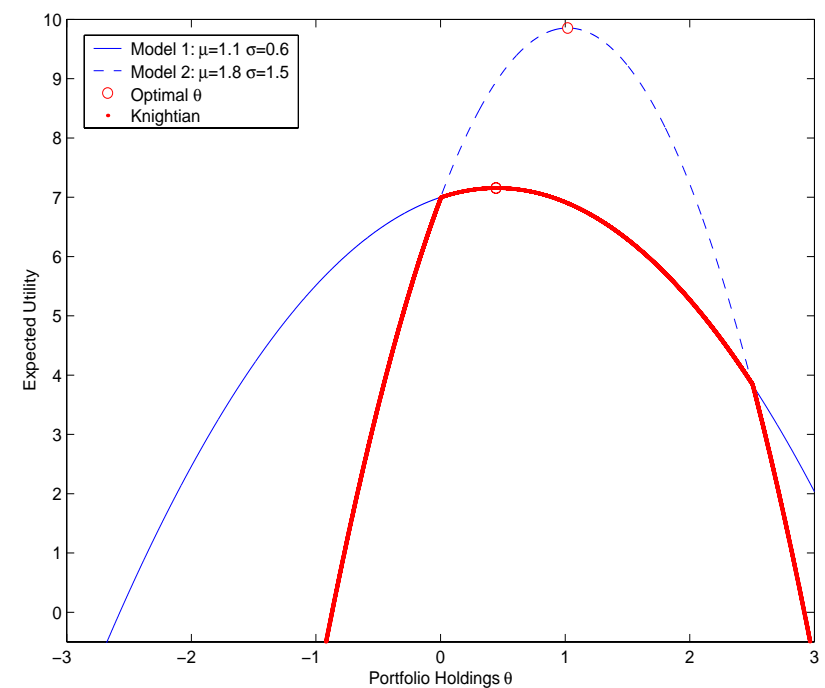

Note: The figure depicts the utility from each of two distributions (low mean/low variance versus high mean/high variance) as a function of the investment in the risky asset $\theta$. In this example, the Knightian-uncertainty portfolio choice is equivalent to assuming the low mean/low variance distribution and Savage expected utility.

of the Knight-optimal portfolio and occurs when

$$
\begin{aligned}
& E_{\pi^{1}}\left[u\left(\omega_{1}+\theta^{1} P_{1}\right)\right]>E_{\pi^{2}}\left[u\left(\omega_{1}+\theta^{1} P_{1}\right)\right] \text { and } \\
& E_{\pi^{2}}\left[u\left(\omega_{1}+\theta^{2} P_{1}\right)\right]>E_{\pi^{1}}\left[u\left(\omega_{1}+\theta^{2} P_{1}\right)\right]
\end{aligned}
$$

In this situation, there is not a clear worst case distribution and the Knight agent acts like neither of the Savage agents $\theta^{K} \neq \theta^{1}$ and $\theta^{K} \neq \theta^{2}$. At $\theta^{K}$, a marginal change in the portfolio alters which distribution is considered worstcase and uncertainty is of first-order importance.

When equation (10) holds, the optimal Knight portfolio is not characterized by a first-order condition. Instead, the optimal portfolio for the Knight individual occurs at the intersection of the utility calculated under the two 
Figure 3: Optimal Portfolio: Quadratic Example 2

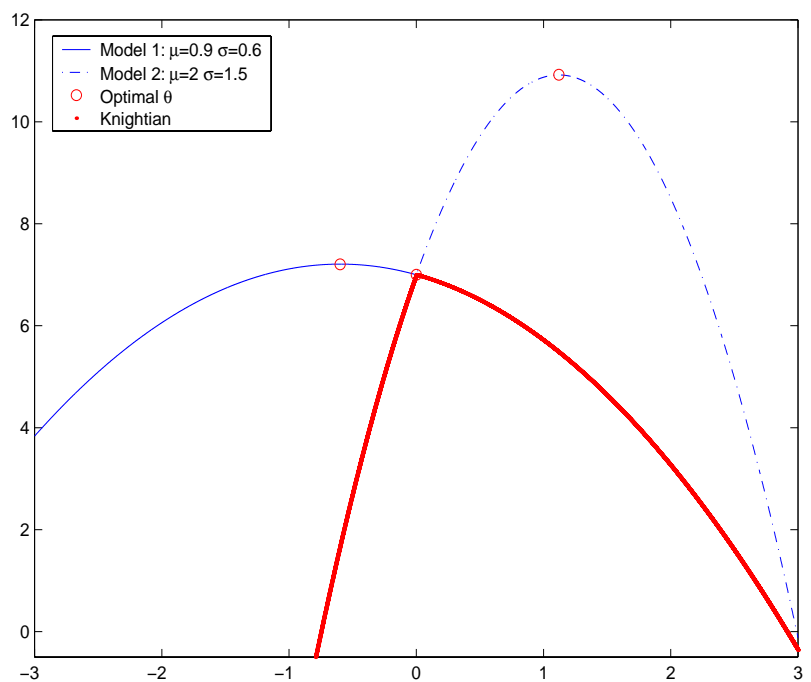

Note: The figure depicts the utility from each of two distributions (low mean/low variance versus high mean/high variance) as a function of the investment in the risky asset $\theta$. In this example, the Knightian-uncertainty portfolio choice differs significantly from the Savage expected-utility choice under either distribution.

distributions. That is, $\theta^{K}$, solves

$$
E_{\pi^{1}}\left[u\left(w_{1}+\theta^{K} P_{1}\right)\right]=E_{\pi^{2}}\left[u\left(w_{1}+\theta^{K} P_{1}\right)\right]
$$

and $\theta^{K}$ lies between $\theta^{1}$ and $\theta^{2} .^{15}$

The behavior of the Knight trader in these two cases is distinct. Consider, for example, how the Knight's optimal portfolio responds to a change in initial income, $w_{0}$. In the situation where the Knight's portfolio is identical to a pessimistic Savage portfolio it is defined by the first order condition (see Figure 2). Differentiating equation (9) implies that $0<\frac{\partial \theta^{K}}{\partial \omega_{0}}<\frac{1}{P_{0}}$. However, in the

\footnotetext{
${ }^{15}$ Equation (11) may have multiple solutions. However, the optimal portfolio is the only solution that lies in the interval between $\theta^{1}$ and $\theta^{2}$. This is because, for Savage individuals, the first-order condition is necessary and sufficient.
} 
case where there is no portfolio-free characterization of the worst-case as in Figure 3, equation (11) determines the optimal portfolio and $\frac{\partial \theta^{K}}{\partial \omega_{0}}=0$. Due to the first-order nature of the uncertainty, the optimal portfolio of the Knight agent is insensitive to changes in initial wealth. This is true even for discrete changes in initial income. As long as equation (10) holds at the new level of income, $\omega_{0}$, even large changes in initial income will not alter the optimal Knight holdings of the risky asset.

\subsubsection{Convex Uncertainty}

Thus far, Knightian uncertainty has been characterized by the discrete set, $\Pi^{K}=\left\{\pi^{1}, \pi^{2}\right\}$. This represents uncertainty between two alternative models. A natural alternative characterization of uncertainty is be to allow mixing between the two discrete models. Consider a case where Knightian uncertainty is defined by the convex set $\Pi^{C}=\left\{\alpha \pi^{1}+(1-\alpha) \pi^{2} \mid \alpha \in[0,1]\right\}$. Since expectations are linear in probabilities, adding the convex hull to the set of possible distributions does not alter behavior. In particular, the optimal portfolio, $\theta^{C}$, for a Knight trader with this convex uncertainty, $\Pi^{C}$, will be identical to a Knight trader with the discrete set of models, $\Pi^{K}$; that is $\theta^{C}=\theta^{K}$. However, since $\Pi^{C}$ is convex, by the min-max theorem,

$$
\max _{\theta}\left\{u\left(c_{0}\right)+\beta \min _{\pi^{\alpha} \in \Pi^{C}} E_{\pi^{\alpha}}\left[u\left(c_{1}\right)\right]\right\}=\min _{\pi^{\alpha} \in \Pi^{C}} \max _{\theta}\left\{u\left(c_{0}\right)+\beta E_{\pi^{\alpha}}\left[u\left(c_{1}\right)\right]\right\}
$$

Therefore, there exists a Savage individual with beliefs $\pi^{\alpha}=\alpha \pi^{1}+(1-\alpha) \pi^{2}$ whose optimal portfolio is identical to the Knight's; that is $\theta^{C}=\theta^{\alpha}$. Figure 4 is identical to Figure 3 except utility is plotted for additional distributions. In this case the optimal Knight portfolio, $\theta^{C}$, is the same as that of a Savage individual whose beliefs are given by $\alpha=0.1$. One can not distinguish between a Savage individual with beliefs $\pi^{\alpha=0.1}$ and Knight trader with uncertainty of $\Pi^{C}$ simply by observing the portfolio choice. However, the two traders are distinguished by other behavior. For example, the Savage individual reacts in the usual way to a change in initial income, $0<\frac{\partial \theta^{\alpha}}{\partial \omega_{0}}<\frac{1}{P_{0}}$. This is not true 
Figure 4: Optimal Portfolio: Convex Uncertainty

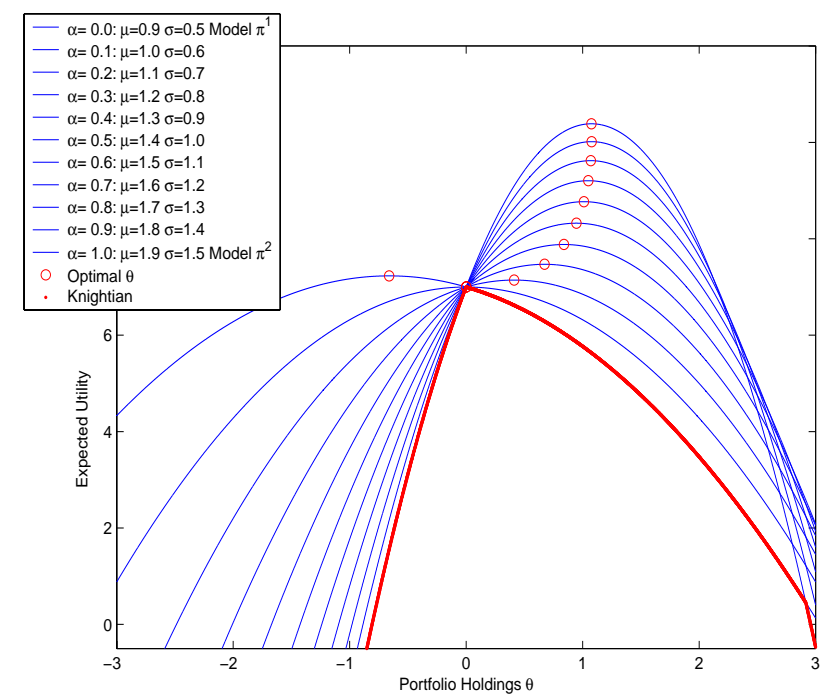

Note: The figure depicts the utility under several of the possible distributions $\Pi^{C}=$ $\left\{\alpha \pi^{1}+\left(1-\alpha \pi^{2} \mid \alpha \in[0,1]\right\}\right)$ as a function of the investment in the risky asset $\theta$. In this case, the optimal Knight portfolio, $\theta^{C}=\theta^{K}$ is the same as a Savage portfolio with $\alpha=0.1, \theta^{\alpha=0.1}$

of the Knight portfolio. As before, $\frac{\partial \theta^{C}}{\partial \omega_{0}}=0$. When initial income changes, the optimal Knight portfolio can still be represented by a particular Savage agent's choice. However, it will be a different-looking Savage. That is, when $0<\alpha<1$, a change in endowment requires a changes in the beliefs if one is to mimic the Knight portfolio with a Savage individual. As in Figure 3, the uncertainty is of first-order importance. Since the relevant aspects of Knightian uncertainty are present in the simple discrete-set characterization, $P i^{K}$, we focus on this specification in the remainder of the paper. 


\subsection{The Market Maker Problem}

Given a characterization of the portfolio problem and the resulting indirect utility, the market-maker problem at period zero in the two-period model is given by

$$
\max _{a, b}\left\{[1-\Phi(a)] U_{a}+[\Phi(a)-\Phi(b)] U_{0}+\Phi(b) U_{b}\right\} .
$$

Recall that the demand for the derivative asset is captured by the arrival of a trader with a valuation $\tilde{v}$ with distribution $\Phi(v)=\operatorname{Prob}(\tilde{v}<v)$. In choosing the bid and ask prices, the tradeoff for the market maker is straightforward. Choosing a high value for the ask will generate more revenue should a highvalue trader arrive. However, it lowers the probability of such a trade actually arriving. Likewise, choosing a low value for the bid will allow the market maker to obtain the future cash flows of the derivative for a low price should a low-value trader arrive, but it lowers the probability of such a trade actually arriving. In both cases, the period-zero income effect that results from a trade is offset by the period-one income effect of the derivative's payoff.

\subsubsection{Example}

To explore the effects of uncertainty on the bid-ask spread, we examine a numerical example of the two period economy. Preferences, $u$, in this example are quadratic and exogenous income, $y_{0}$ and $y_{1}$, is constant. The example considers a market-maker for a call option $X\left(P_{t}\right)=s \max \left(0, P_{1}-1.5\right)$ with $s=1$. The demand for the derivative is summarized by the arrival of a random willingness-to-trade $\tilde{v}$ with $\Phi(v)$ as uniform on the interval $[0.5,1.5]$. The current price, $P_{0}=0.9$. The distribution(s) of the underlying asset's period one payoff, $P_{1}$, is assumed to be binomial with equally likely values of

$$
\tilde{P}_{1}=\left\{\begin{array}{l}
\mu_{m}+\sigma_{m} \\
\mu_{m}-\sigma_{m}
\end{array}\right.
$$


Figure 5: Bid and Ask as Uncertainty Increases

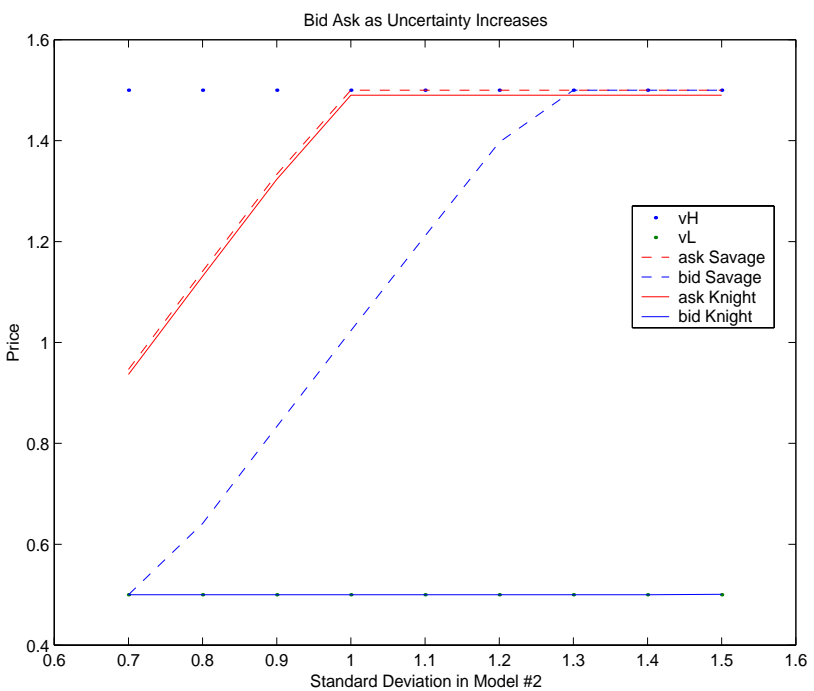

Note: The expected-utility market maker is willing to raise his bid price as volatility increases, whereas the market maker with an aversion to Knightian uncertainty does not.

which implies a mean of $\mu_{m}$ and a variance of $\sigma_{m}^{2}$. There are two possible distributions or models, $\pi^{m}$ for $m \in\{1,2\}$, for the underlying asset. Two Savage market-makers are captured by $\Pi^{1}=\left\{\pi^{1}\right\}$ and $\Pi^{2}=\left\{\pi^{2}\right\}$. The Knight market-maker with uncertainty aversion, is represented by $\Pi^{K}=\left\{\pi^{1}, \pi^{2}\right\}$. Model $m=1$ has a mean and standard deviation variance of 0.9 . Model 2 has a mean and standard deviation that we range from 0.7 to 1.8. For the different economies we consider, as the distribution in Model 2 moves further away from the distribution in Model 1, uncertainty increases.

Figure 5 depicts the effect on the bid and ask prices as uncertainty increases. The market maker with an aversion to Knightian uncertainty maintains a constant bid price, whereas a Savage market maker will allow the bid price to rise to reflect the higher value of the derivative. The affect that this has on the bid-ask spread is depicted in Figure 6, and the affect on the prob- 
Figure 6: Bid-Ask Spread as Uncertainty Increases

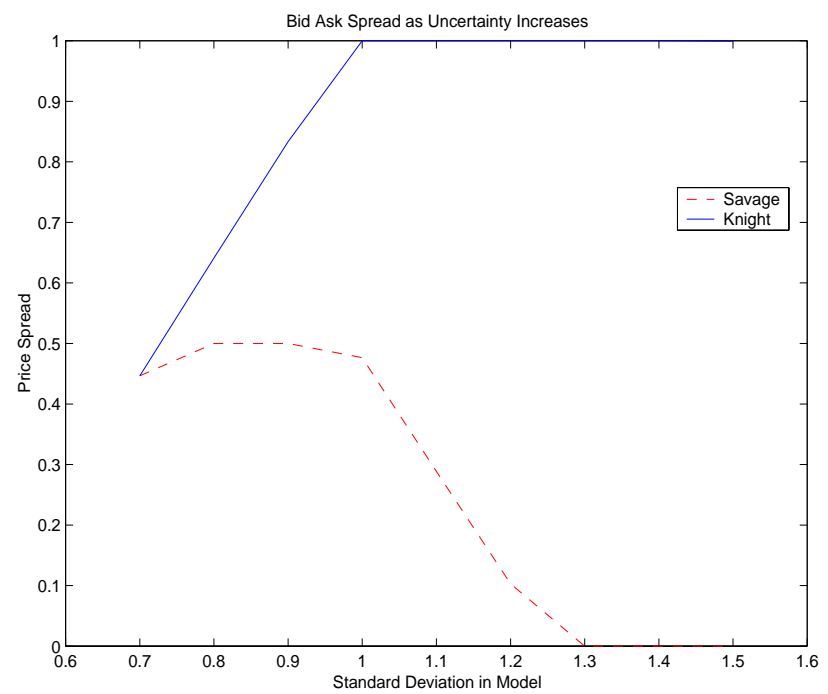

ability of a trade is depicted in Figure 5. As depicted in these figures, it is possible for model uncertainty to completely eliminate the willingness of a uncertainty-averse market-maker to provide liquidity, while a market maker who is not averse to this uncertainty, but is merely a pessimistic expected utility maximizer, will continue to provide liquidity.

\subsubsection{Determinants of Spreads}

In the preceding example, the liquidity provided by a Knight market-maker was always less than or equal to the liquidity provided by a market maker with Savage preferences. To explore why this occurs, consider the first-order conditions for the market-maker problem in equation (13).

$$
\frac{1-\Phi(a)}{\phi(a)}\left(\frac{\partial U_{a}}{\partial a}\right)=U_{a}-U_{0}
$$


Figure 7: Probability of a Trade as Uncertainty Increases

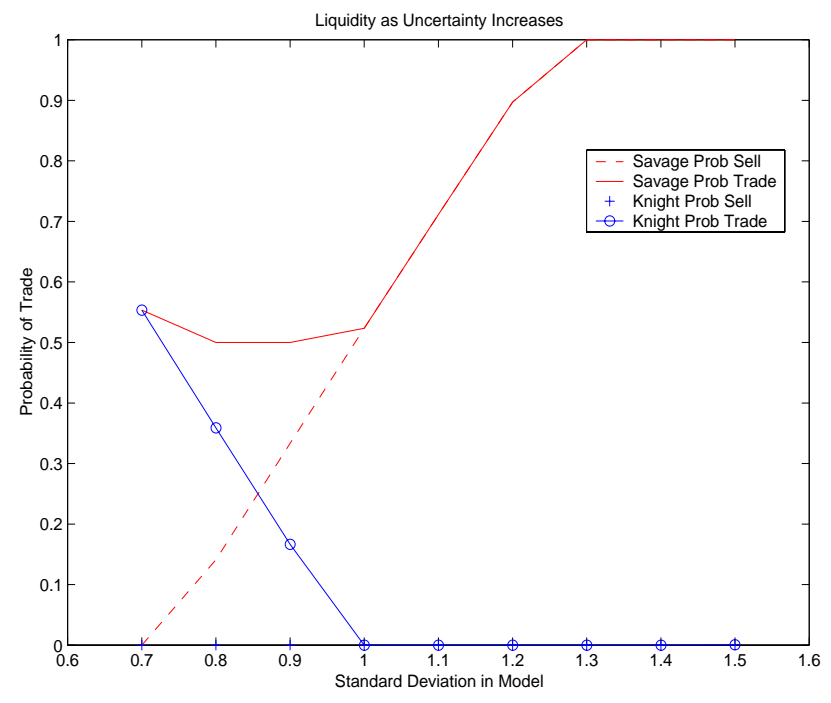

$$
\frac{\Phi(b)}{\phi(b)}\left(-\frac{\partial U_{b}}{\partial b}\right)=U_{b}-U_{0} .
$$

Denote the optimal portfolio from the solution equation (7) as $\theta_{a}^{i}$ when the market maker has received $a$ and is short the derivative $(d=-1)$ and define $\theta_{b}^{i}$ and $\theta_{0}^{i}$ analogously (for $i \in\{1,2, K\}$ ). For both Savage and Knight traders $\frac{\partial U_{a}}{\partial a}$ and $\frac{\partial U_{b}}{\partial b}$ are given by

$$
\begin{aligned}
& \frac{\partial U_{a}}{\partial a}=u^{\prime}\left(y_{0}+a-\theta_{a}^{i} P_{0}\right) \\
& \frac{\partial U_{b}}{\partial b}=-u^{\prime}\left(y_{0}-b-\theta_{b}^{i} P_{0}\right) .
\end{aligned}
$$

For Savage preferences, equation (16) is the envelope condition. For the Knight market-maker, the envelope condition holds when the optimal portfolio is identical to a worst-case Savage and is defined by the first-order condition (9). When there is no portfolio-free characterization for the worst-case distribution as in equation (10) and Figure 3, equation (16) holds since $\frac{\partial \theta_{a}^{K}}{\partial a}=0$ and 
$\frac{\partial \theta_{b}^{K}}{\partial b}=0$. This simplifies the characterization of the optimal bid and ask prices since Knightian uncertainty only effects the right-hand-side of equation (15) indirectly through the optimal portfolio. Equation (16) is a useful property since it facilitates decomposing the ask-bid first-order condition to isolate the effects of Knightian uncertainty.

Market-making activity has implications for income at both date zero and date one (see equation (8)). Denote $U_{b=0}$ as the total indirect utility from a long position in the derivative acquired at zero cost. Similarly, we can denote $U_{a=0}$ as the total indirect utility from a short position in the derivative when no compensating period-zero ask is received. Using this notation and equation (16), we can re-write the equation (15) to decompose the first-order condition to highlight period-zero and period-one income effects of derivative trade.

$$
\begin{aligned}
& -\frac{1-\Phi(a)}{\phi(a)} u^{\prime}\left(y_{0}+a-\theta_{a}^{i} P_{0}\right)+U_{a}-U_{a=0}=U_{0}-U_{a=0} \\
& \frac{\Phi(b)}{\phi(b)} u^{\prime}\left(y_{0}-b-\theta_{b}^{i} P_{0}\right)+U_{b=0}-U_{b}=U_{b=0}-U_{0} \\
& \text { trade } \underbrace{\text { period } 1}_{\text {period } 0} \\
& \text { arrival income income }
\end{aligned}
$$

Consider the optimal ask price given by equation (17a). The left-hand side of (17a) captures the basic trade-off in terms of period zero income. The first term shows that a larger ask price decreases the likelihood of a trade arrival (and decreases marginal utility of period-zero consumption if a trade arrives). The second term, $U_{a}-U_{a=0}$, captures the benefit of a larger ask price has on utility if a trade does occur. The left-hand side of (17a) is increasing in $a$. The right-hand side of (17a), $U_{0}-U_{a=0}$, captures only the disutility from the effect that a short position in the derivative has on period-one income. Since $X(P) \geq 0$ a short position, given no adjustment in period zero income $(a=0)$, makes the market-maker worse off $\left(U_{0}-U_{a=0}>0\right)$. Since the right-hand side 
Figure 8: Utility-Based Spreads

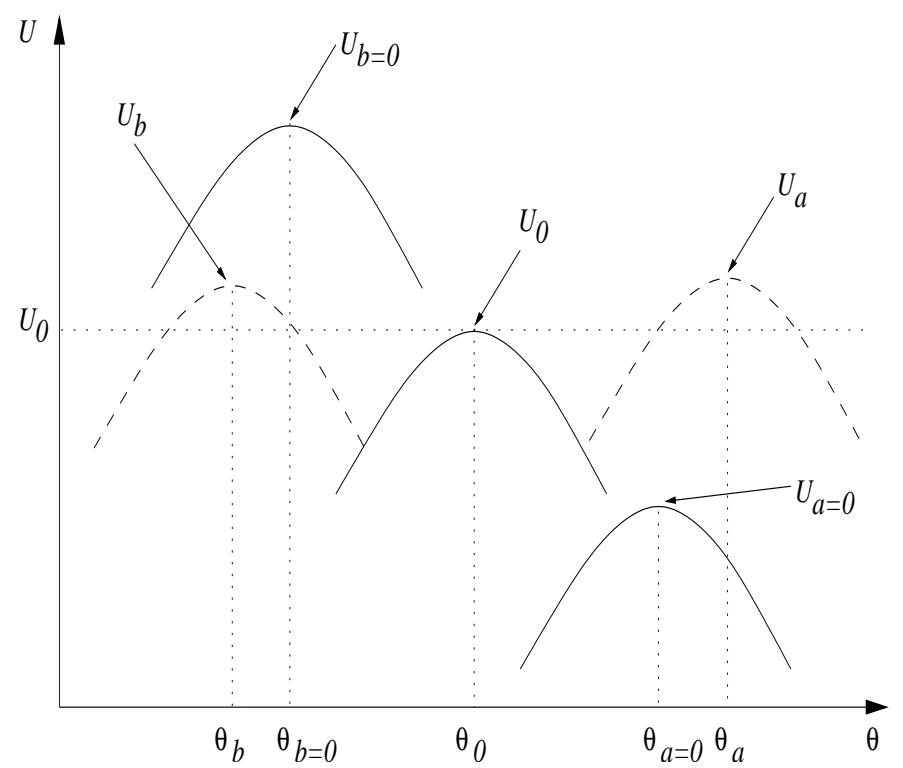

Note: The figure depicts the utility as a function of the investment in the risky asset $\theta$. The solid lines depict the utility under the case where the market-maker is long the derivative at cost $b=0$ (left), has no position in the asset (center), is short the derivative at ask price of zero, $a=0$ (right). The peak of each of these three lines determines the right-hand-side of equation (17). The dashed lines show the utility in the long (left) and short (right) cases given the optimal bid and ask price.

includes only the period-one income effect of the derivative cash-flow, it is independent of $a$. The decomposition for equation (17b) has an analogous interpretation. The left-hand side of (17b) increasing in the bid price, $b$, and the right-hand side independent of the bid, $b$.

Based on equation (17), all else equal, ask prices are higher when $U_{0}-U_{a=0}$ is large and bid prices are lower when $U_{b=0}-U_{0}$ is small. In this case, spreads are large and the market is less liquid. Figure 8 plots utility as a function of the investment in the risky asset $\theta$ and is analogous to Figures 2 and 3. The solid lines depict the utility under the case where the market-maker is long the 
derivative at cost $b=0$ (solid line at left), has no position in the asset (solid line in center), is short the derivative at ask price of zero, $a=0$ (solid line at right). The distance between the peaks determines the right-hand-side of equation (17). If the distance $U_{0}-U_{a=0}$ is large, the market-maker's optimal ask will be large to offset the large utility cost of the short-position at period one. At the optimal ask, $U_{a}$ (peak of dashed line on right) must lie above $U_{0}$. At the optimal ask, $U_{a}-U_{0}>0$ since the market maker can choose to set the ask price arbitrarily large and drive the probability of the short position to zero. ${ }^{16}$ Similarly, if the distance between $U_{b=0}$ and $U_{0}$ is small, the benefit from being long the derivative is small and the market-maker has little room to bid aggressively for the derivative. Again, note that at the optimal bid $U_{b}$ (peak of dashed line on left) must lie above $U_{0}$.

The decomposition in (17) is also helpful since it highlights the effect of Knightian uncertainty on bid-ask spreads. Since the left-hand-sides of (17) are concerned with the impact of ask and bid prices on period zero income, uncertainty about the distribution of period one income plays no direct role. The only way the left-hand-sides of (17) can behave differently for a Savage market-maker relative to a Knight market-maker is through differences in the optimal portfolio. In contrast, since the right-hand-sides of (17) concerns period one income, uncertainty has a direct effect.

Knightian uncertainty will lower all three levels of utility in Figure 8. That is relative to the Savage market makers, $U_{a}^{K}<U_{a}^{i}, U_{0}^{K}<U_{0}^{i}$, and $U_{b}^{K}<U_{b}^{i}$, for $i=1,2$. Consider, for example, the case where the optimal portfolio for the Knight and the Savage market-makers, with no position in the derivative, yields consumption that is close to riskless, and, hence, without ambiguity. In this case, $U_{0}^{K} \approx U_{0}^{i}$ and a Knightian market-maker bid-ask spread will be larger than a Savage. That is: $a^{K} \geq a^{i}$ and $b^{K} \leq b^{i}$ (for $i=1,2$ Savage market makers). However, if $U_{0}^{i}$ is affected by uncertainty, then it is possible that the Knight market-maker posts a bid or ask that is more aggressive. This occurs when the the derivative position "hedges ambiguity." In particular,

\footnotetext{
${ }^{16}$ Substitute equation (16) into (15) and not the left-hand side is positive.
} 
the difference $U_{0}^{K}-U_{a=0}^{K}$ may be smaller for a Knight market-maker than a Savage if the worst-case distribution in the $U_{0}^{K}$ case differs from the case in $U_{a=0}^{K}$. In this case, the optimal Knight market-maker may post a more aggressive (lower) ask.

\subsubsection{Market Structure}

Non-zero bid-ask spreads are, of course, directly related to our assumption of a monopolist market-maker. Interestingly, the difference between bid-ask spread of a Knight market maker relative to a Savage market-maker is also closely linked to the market structure. For example, consider the effect of making a small trade in a call option. Define $X\left(P_{1}\right)=s \max \left(P_{1}-x, 0\right)$ and let $s \rightarrow 0 .{ }^{17}$ Since period-one income is continuous in $s$, indirect utility in equation (7) is continuous in $s$ even under Knightian uncertainty. Therefore the right-hand-sides of equation (17) are both zero as $s \rightarrow 0$. Therefore, Knightian uncertainty can have no direct impact on bid-ask spreads. It will only affect spreads indirectly through the effect on the optimal portfolio..

More generally, uncertainty aversion itself cannot be the source of a bid-ask spread. Consider the case where, in addition to arbitrarily small trades in the derivative, the market-maker faces Bertrand competition. In Bertrand competition, the ask prices will simply be the compensating period zero income that offsets the disutility from a short position in the derivative security. That is the ask price, $a$, solves $U_{a}-U_{0}=0$ and the bid price, $b$, solves $U_{b}-U_{0}=0$. Figure 9 plots the indirect utility (at the optimal portfolio) as a function of the position in the derivative, $d$, and the size of derivative payoff, $s$, with $X\left(P_{1}\right)=s \max \left(P_{1}-1.5,0\right)$ (the same call option as in the previous example). This plot lets us consider arbitrarily small long and short positions in the derivative. The plot shows Savage expected utility preferences under the two possible distributions. For the Savage market-maker, the indirect utility

\footnotetext{
${ }^{17}$ Ask and bid prices need to redefined to be "per unit" so that the market maker pays $s \cdot b$ to go long and gets $s \cdot a$ to go short.
} 
Figure 9: Total Indirect Utility as size of derivative payoff, $s$, Varies Continuously

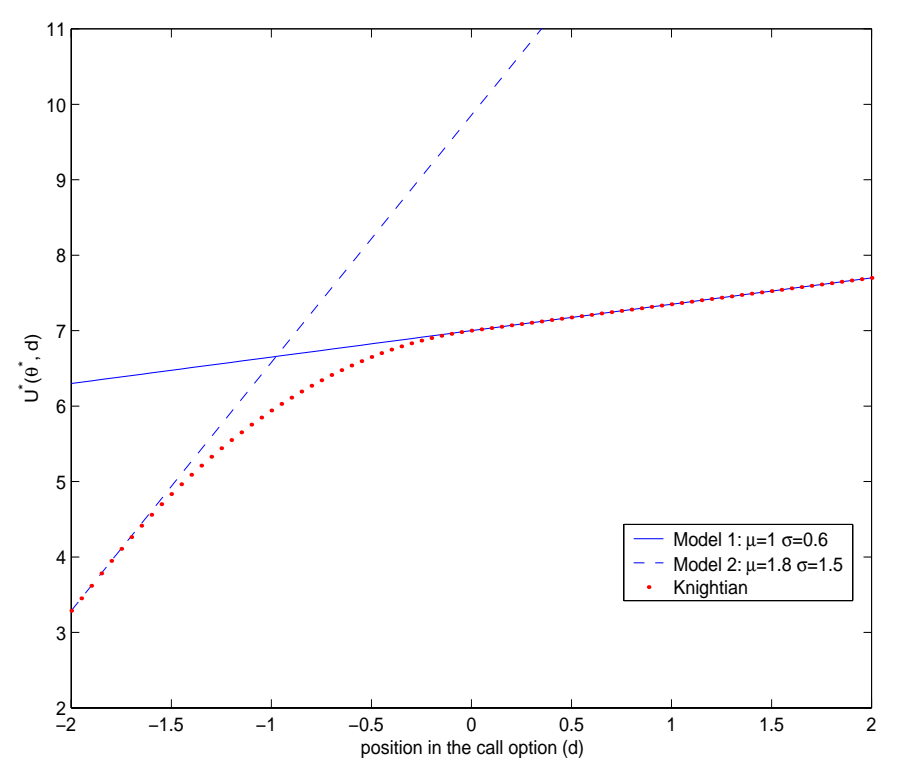

For fixed parameters, the size of the position in the derivative, $d \cdot s$, is varied. The payoff in the derivative is $X\left(P_{1}\right)=s \max \left(P_{1}-1.5,0\right)$ and trades are discrete $d \in\{-1,0,1\}$. The total utility shown is at the optimal portfolio.

is differentiable in $s$. In particular, small positive and small negative positions in the derivative have an equal (but opposite) effect on utility. Therefore, bid-ask spreads are zero (i.e., $a=b$ ). For the Knightian-uncertain marketmaker in the same setting, this is true almost everywhere. The lower line in Figure 9 represents the indirect utility of the Knightian market-maker. For small and large values of $s$, the Knightian indirect utility is the same as the worst case Savage (as in Figure 2). For intermediate values of $s$, the Knightian indirect utility is strictly lower as in the case when the uncertainty aversion is of first-order importance (see Figure 3). However, only at two points in Figure 9 is the Knightian market maker's indirect utility kinked (non-differentiable) and, hence, only at these two points does the ask price exceed the bid. These kink points occur where both (9) and (10) simultaneously occur. Since these 
two points are unlikely to occur (of zero measure), when markets are frictionless, Knightian uncertain preferences are not sufficient to generate a bid-ask spread. ${ }^{18}$

To apply our model to the market collapse related to the 1998 Russian bond default, for example, it is not sufficient that a market-maker like LTCM is uncertainty averse. It is also important the the trades in the derivative be large and that the market-maker has some degree of market power in order for Knightian uncertainty to effect market liquidity. Interestingly, the Bank of International Settlements (1999) lists the increased concentration of marketmaking activity as one of the factors that amplified the crisis. Given the important interaction between market frictions and Knightian uncertainty, we leave the question of an optimal market design given uncertainty to future research.

\subsubsection{Hedging Derivatives Positions}

Figures 2 and 3 helped characterize the optimal Knight portfolio independent of the market-making activity. However, it is interesting to consider how the optimal portfolio responds to a change in the position in the derivative. Looking back at equation (17), the optimal portfolio appears in most of the terms. Therefore, Knightian uncertainty has an effect on bid-ask spreads indirectly through the optimal portfolio. Moreover, hedging derivative positions in the underlying markets is an important facet of market making. The popularity of models like Black and Scholes (1973) is in their ability to provide an offsetting trade that hedges a position in the derivative. The ability to hedge positions is essential for a financial intermediary like LTCM to leverage their capital into

\footnotetext{
${ }^{18}$ This is in contrast to comments in both Dow and Werlang (1992) and Epstein and Wang (1995). More generally, in representative agent, endowment economies, Knightian uncertainty is rarely locally relevant. For example, Knightian uncertainty can create an indeterminacy in equilibrium (Epstein and Wang (1994) and (1995)). However, in economies with aggregate risk and uncertainty only about aggregate endowment, the representative agent's Knightian utility is differentiable and prices are unique. See Epstein (2001).
} 
Figure 10: Hedging a Short Call Position: "Natural"

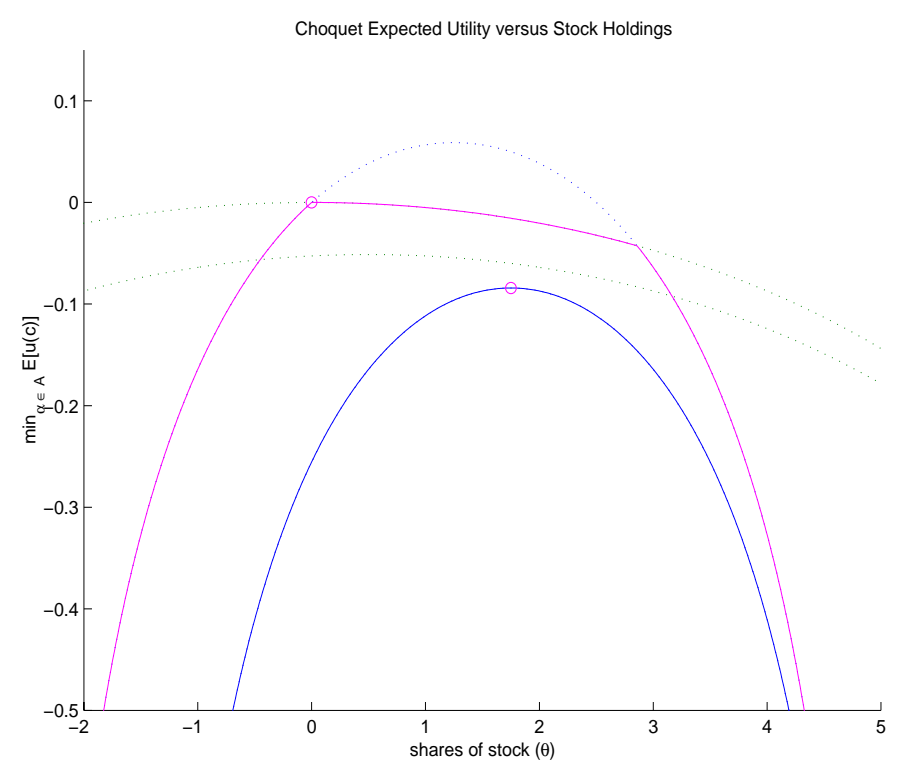

Note: The figure depicts the utility from each of two distributions as a function of the investment in the risky asset $\theta$. The lower line for each distribution represents is from a short position in the call option. The "o" is optimal portfolio of the Knight market-maker given no position, $\theta_{0}^{K}$ (upper left), and given a short position in the call option, $\theta_{a=0}^{K}$ (lower right)

large positions. In our two-period example, we can also look at the effect of model uncertainty on the trades used to hedge a position in the derivative. In our setting, the market is not complete, so market-makers cannot offset the full position in the derivative. However, the change in the optimal portfolio due to a trade in the derivative captures the hedging behaviour of the marketmaker. For example, consider the optimal portfolio in the case where there is no derivative position relative to a short position in the derivative. Define the "hedge portfolio" induced by this short position in the call as $\theta_{a}^{i}-\theta_{0}^{i}$.

Figure 10 depicts this hedge portfolio for a short call position in a log-utility version of the two-period model. (The switch to logarithmic utility adds some asymmetry to the utility function relative to the quadratic case.) In this 
Figure 11: Hedging a Short Call Position: "Unnatural"

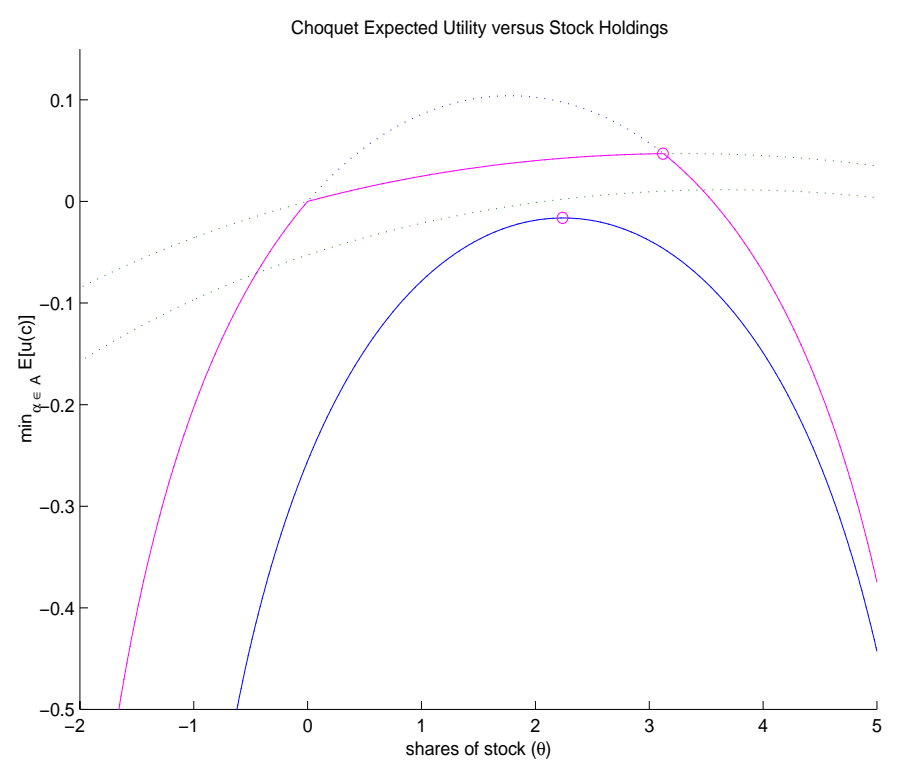

Note: The figure depicts the utility from each of two distributions as a function of the investment in the risky asset $\theta$. The lower line for each distribution represents is from a short position in the call option. The "o" is optimal portfolio of the Knight market-maker given no position, $\theta_{0}^{K}$ (upper right), and given a short position in the call option, $\theta_{a=0}^{K}$ (lower left)

example, the short call position is hedged by buying more of the underlying asset. This is a natural hedging strategy and is consistent with the behavior of any Savage market maker. However, with a slightly different configuration of uncertainty, Figure 11 depicts a very strange situation. The short position in the call option is hedged by reducing investment in the underlying asset. The optimal portfolio, in response to a short position in the call option, has shifted left. The reason for this odd behavior is that, in this case, when $d=0$, the optimal portfolio was not given by the solution to the first condition as in equation (9) and uncertainty is of first-order importance. In this case, the optimal portfolio of the Knight trader does not resemble either of the Savage traders. Since the optimal portfolio is given by (11), it does not respond in 
a natural way to the derivative position. When the optimal portfolio is given by (11), the optimal hedge portfolio is not constrained to be either positive or less than one as it would be for Savage market makers.

\section{Infinite-Horizon Model}

Building on our understanding of the two-period example, we now return to the infinite-horizon model summarized in equation (6). We focus on a relatively simple portfolio problem so that we can highlight the role of market making in the derivative. Assume that the underlying security price follows a two-state Markov process with $P_{t} \in\{0.75,1.25\}$ with transition probabilities specified below. To ensure that the portfolio problem is well specified, it is necessary to assume the asset also carries a stochastic dividend. Without some additional cash-flow, the optimal portfolio is an arbitrarily large short-sale position in the case $P_{t}=1.25$. Therefore, we assume the underlying asset pays a dividend that also follows a two state Markov process, $\delta_{t} \in\{0,0.4\}$. As in the previous section, we will consider two Savage market makers with beliefs, $\Pi^{1}=\left\{\pi^{1}\right\}$ and $\Pi^{2}=\left\{\pi^{2}\right\}$, and a Knight market maker with uncertainty represented by $\Pi^{K}=$ $\left\{\pi^{1}, \pi^{2}\right\}$. For both possible models, $\pi^{1}$ and $\pi^{2}$, the states are i.i.d.. The two price and two dividend states produces a four state Markov process of $\left(P_{t}, \delta_{t}\right)$ $\in\{(0.75,0),(0.75,0.4),(1.25,0),(1.25,0.4)\}$ with transition probabilities,

$$
\begin{aligned}
\pi^{1}= & {\left[\begin{array}{llll}
0.1875 & 0.5625 & 0.0625 & 0.1875 \\
0.1875 & 0.5625 & 0.0625 & 0.1875 \\
0.1875 & 0.5625 & 0.0625 & 0.1875 \\
0.1875 & 0.5625 & 0.0625 & 0.1875
\end{array}\right] } \\
\pi^{2}= & {\left[\begin{array}{llll}
0.1250 & 0.1250 & 0.3750 & 0.3750 \\
0.1250 & 0.1250 & 0.3750 & 0.3750 \\
0.1250 & 0.1250 & 0.3750 & 0.3750 \\
0.1250 & 0.1250 & 0.3750 & 0.3750
\end{array}\right] . }
\end{aligned}
$$


This distribution produces asset returns that are state-dependent. For distribution $\pi^{1}$, a more pessimistic view, the mean (standard deviation) asset return is $0.63(0.36)$ when $P_{t}=0.75$ and $-0.02(0.22)$ when $P_{t}=1.25$. The $\pi^{2}$ distribution is more optimistic with mean (standard deviation) asset return of $0.73(0.40)$ in the $P_{t}=0.75$ states and $0.04(0.24)$ in the $P_{t}=1.25$ states. Other parameters used in the example are: utility is log, exogenous income is constant at $y_{t}=12.750$, and $\beta=0.8$.

\subsection{Portfolio Choice}

The optimal portfolio in the case where there is no market-making activity, is shown in Figure 12. In each state, the Knight portfolio policy lies between the two Savage portfolio policies. This feature is similar to the discussion of the two period example of Figures 2 and 3. Unlike the Savage portfolio, the Knight portfolio policy has a region that is flat. In this region, the uncertainty is of first-order importance since there is no portfolio-free characterization of the worst-case distribution and the optimal portfolio, $\theta_{t}^{K}$, is independent of the asset holdings at the start of the period, $\theta_{t-1}^{K}$.

In the absence of market-making, Knightian uncertainty does not dramatically alter the portfolio behavior of a trader. While the optimal policy differs in the case of a Knight trader, it does not, by itself, have a dramatic effect on the time-series behavior of the portfolio holdings. To see this consider the simulation presented in Figure 13. Since there are two possible probability measures describing the evolution of price and dividend, the results show the simulation conducted under both distributions $\pi^{1}$ and $\pi^{2}$. The time-series behavior of the optimal Knight portfolio is constrained by the fact that it is bounded by the Savage-optimal portfolios state-by-state. Knight portfolio is never dramatically different than the Knight. 
Figure 12: Portfolio Policy for Two Savage Traders and a Knight Trader
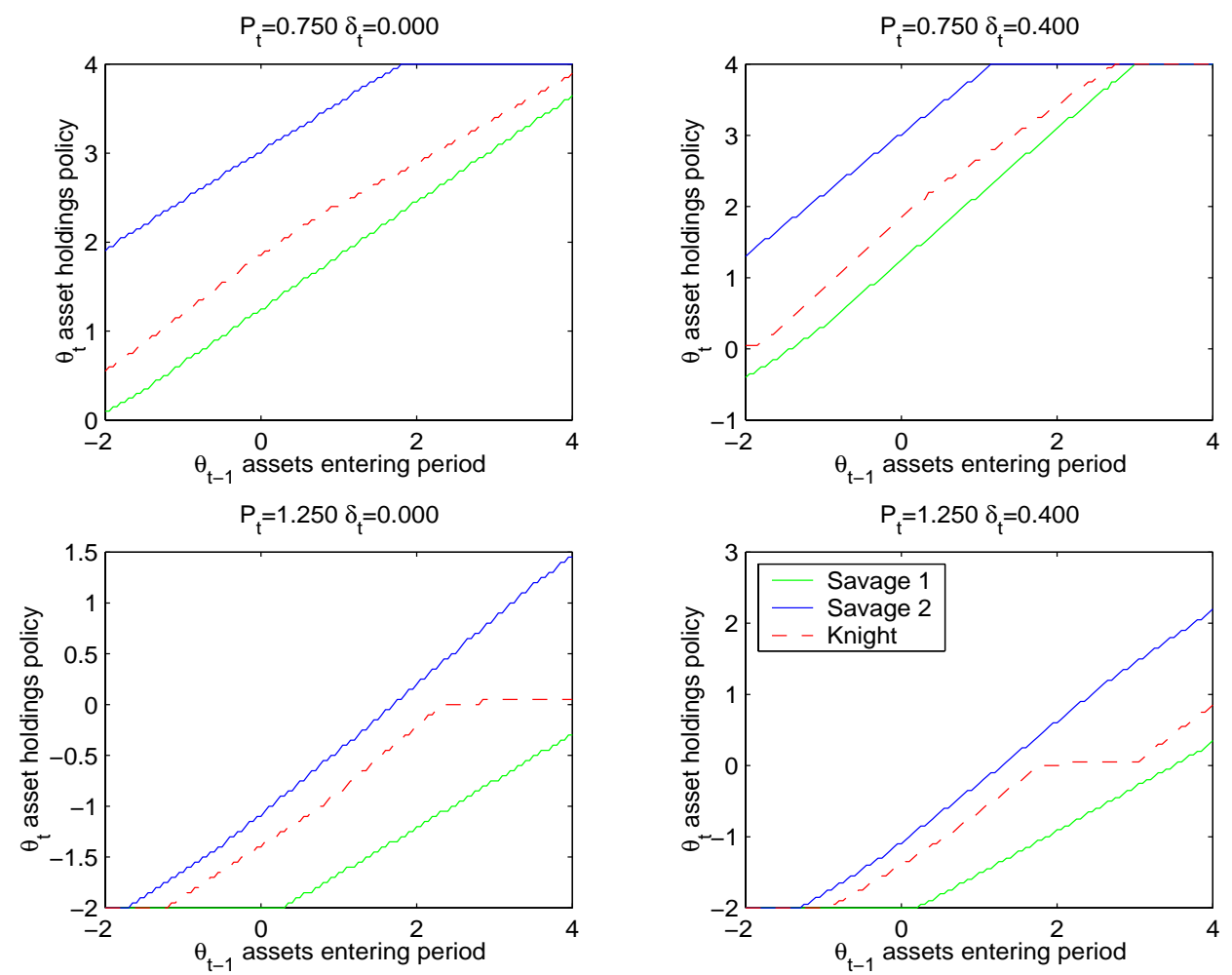

The optimal portfolio, $\theta^{i}$, as a function of the previous asset holdings, is shown. Each sub-plot is a different value of the price-dividend state. The portfolio policy is shown for a Savage trader with beliefs $\Pi^{1}=\left\{\pi^{1}\right\}$, a Savage trader with $\Pi^{2}=\left\{p i^{2}\right\}$, and an uncertainty averse Knight trader with beliefs $\Pi^{K}=\left\{\pi^{1}, \pi^{2}\right\} \cdot \pi^{1}$ and $\pi^{2}$ are defined in equation (18). 
Figure 13: Optimal Portfolio Time Series
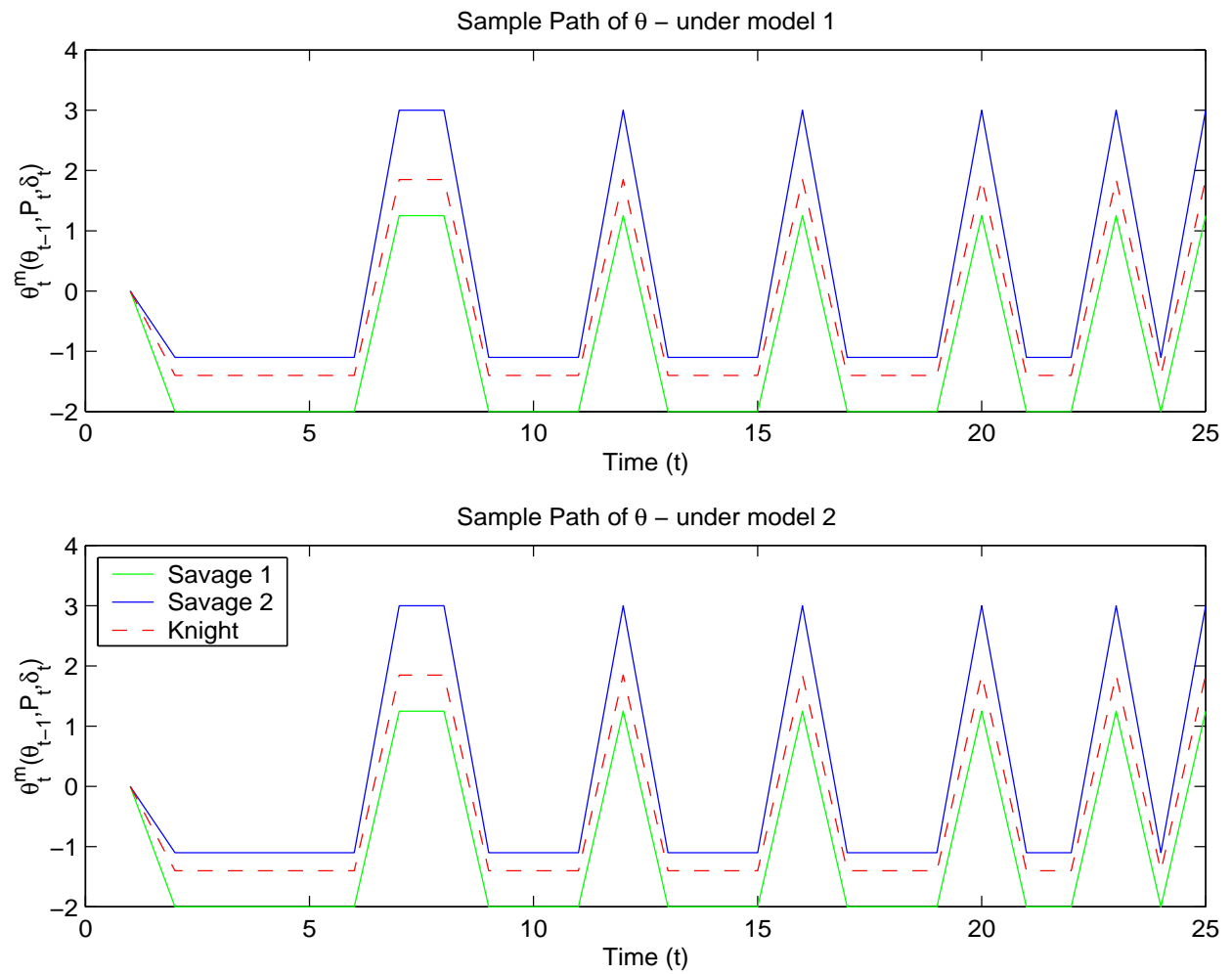

For a simulation of the economy, the optimal realized portfolio, $\theta_{t}^{i}$, is shown for three traders: a Savage market maker with beliefs $\pi^{1}$, a Savage with beliefs $\pi^{2}$, and a Knight market maker with uncertainty averse beliefs represented by $\Pi^{K}=\left\{\pi^{1}, \pi^{2}\right\}$. One period of the simulation consists of drawing a price $P_{t}$ and a dividend $\delta_{t}$ The top panel is simulated under $\pi^{1}$ and the bottom panel is simulated under $\pi^{2}$ (see equation (18) for parameters). 


\subsection{Market-Maker Policies}

We use the same example to consider the infinite-horizon version of the marketmaker problem. The derivative asset is a call option based on the ex-dividend price; that is $X\left(P_{t}\right)=s \max \left(P_{t}-x\right)$. We set the strike price at $x=1.0$ and the derivative size at $s=1.0$. The demand for the derivative is summarized by the arrival of a random willingness-to-trade $\tilde{v}$, where $\tilde{v}$ is distributed uniformly on the interval [0.1,0.2]. Again, we consider the behavior of the two Savage market makers and an uncertainty averse, Knight, market maker.

Figures 14 and 15 summarize the bid and ask policy for the Savage market maker with beliefs $\pi^{1}$ and $\pi^{2}$ respectively. The figure shows the probability of a trade occurring, $1-\left[\Phi\left(a_{t}\right)-\Phi\left(b_{t}\right)\right]$, as a function of the state variables. For the Savage market-maker with beliefs $\pi^{1}$, the bid and ask prices for the derivative are close to constant. The bid and ask prices are set such that the probability of trade is close to 0.5. For the Savage market-maker with the more optimistic beliefs of $\pi^{2}$ (see equation (18)), the probability for trade is slightly higher in the case where the underlying price is low $\left(P_{t}=0.75\right)$. Note, for both Savage market makers, the optimal bid-ask policy is not that sensitive to the position in the underlying security, $\theta_{t-1}$ (not sensitive to current wealth).

Figure 16 summarizes the bid and ask policy for the uncertainty averse Knight market-maker. Notice that the bid-ask behavior, reflected in the probability of trade, is much more sensitive to the incoming asset position, $\theta_{t-1}$. It is also the case that the probability of trade can fall quite low (to 0.3). The low probability of trade for the Knight market-maker coincides with the case where the optimal portfolio is not sensitive to initial wealth since there is no portfolio-free worst-case distribution and the portfolio is not characterized by a first-order-condition. Figure 17 shows the portfolio policy. Recall that the optimal asset position is chosen after the realization of the trade in the derivative and so depends on both previous, $d_{t-1}$, and current, $d_{t}$, position in the derivative. (The asset policy function for the two Savage traders is similar to that shown in Figure 12, so it is not repeated.) The regions where the 
Figure 14: Probability of Trade - Savage $\pi^{1}$
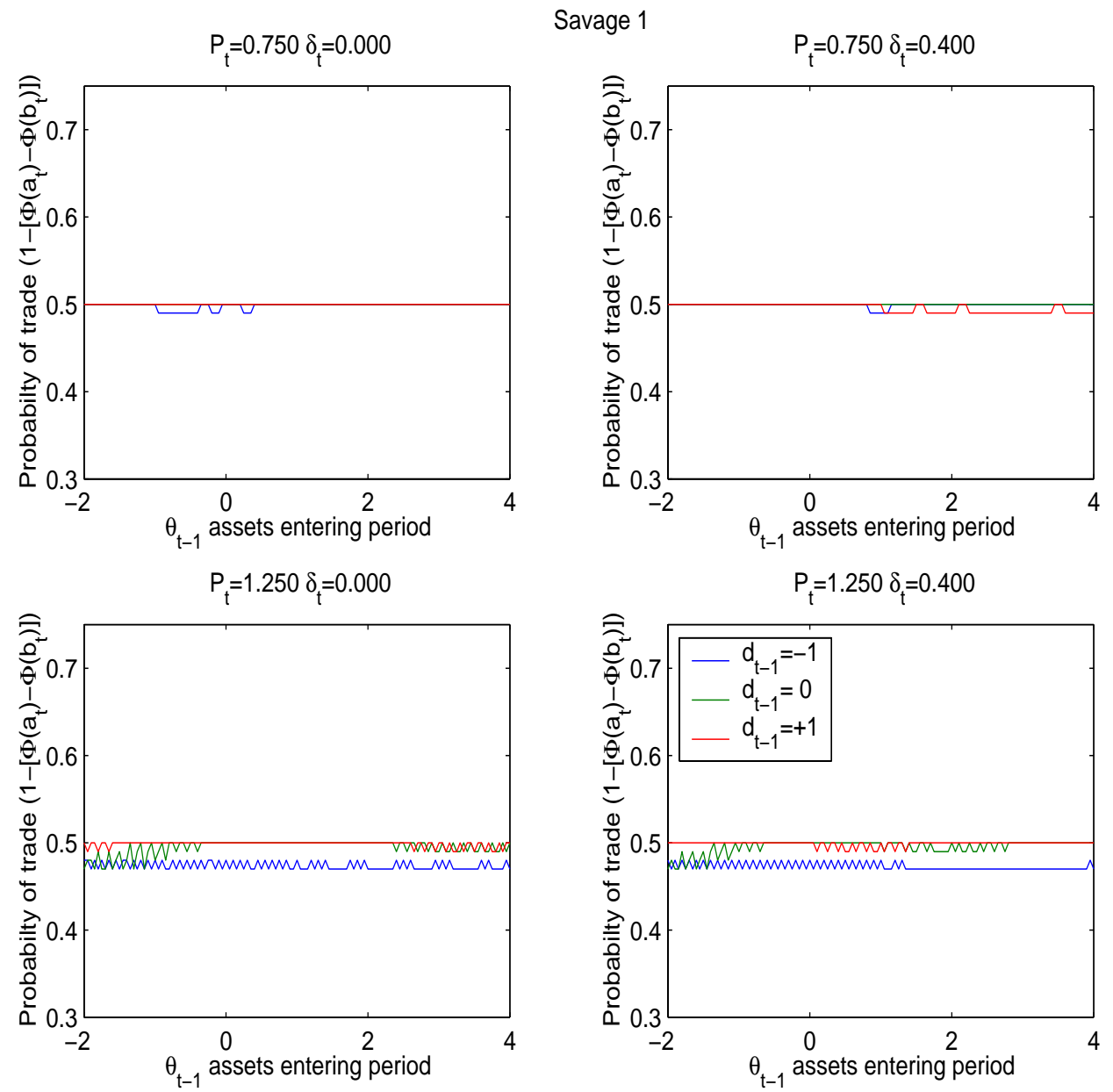

The figure shows the probability of a trade occurring given the bid and ask policy that solves equation (6) for the Savage market-maker with beliefs $\pi^{1}$. The probability of a trade is calculated as $1-\left[\Phi\left(a_{t}\right)-\Phi\left(b_{t}\right)\right]$. The probability of as a function of the state variables: previous position in the derivative, $d_{t-1}$ previous position in the portfolio, $\theta_{t-1}$, current asset price, $P_{t}$, and current asset dividend, $\delta_{t}$. 
Figure 15: Probability of Trade - Savage $\pi^{2}$

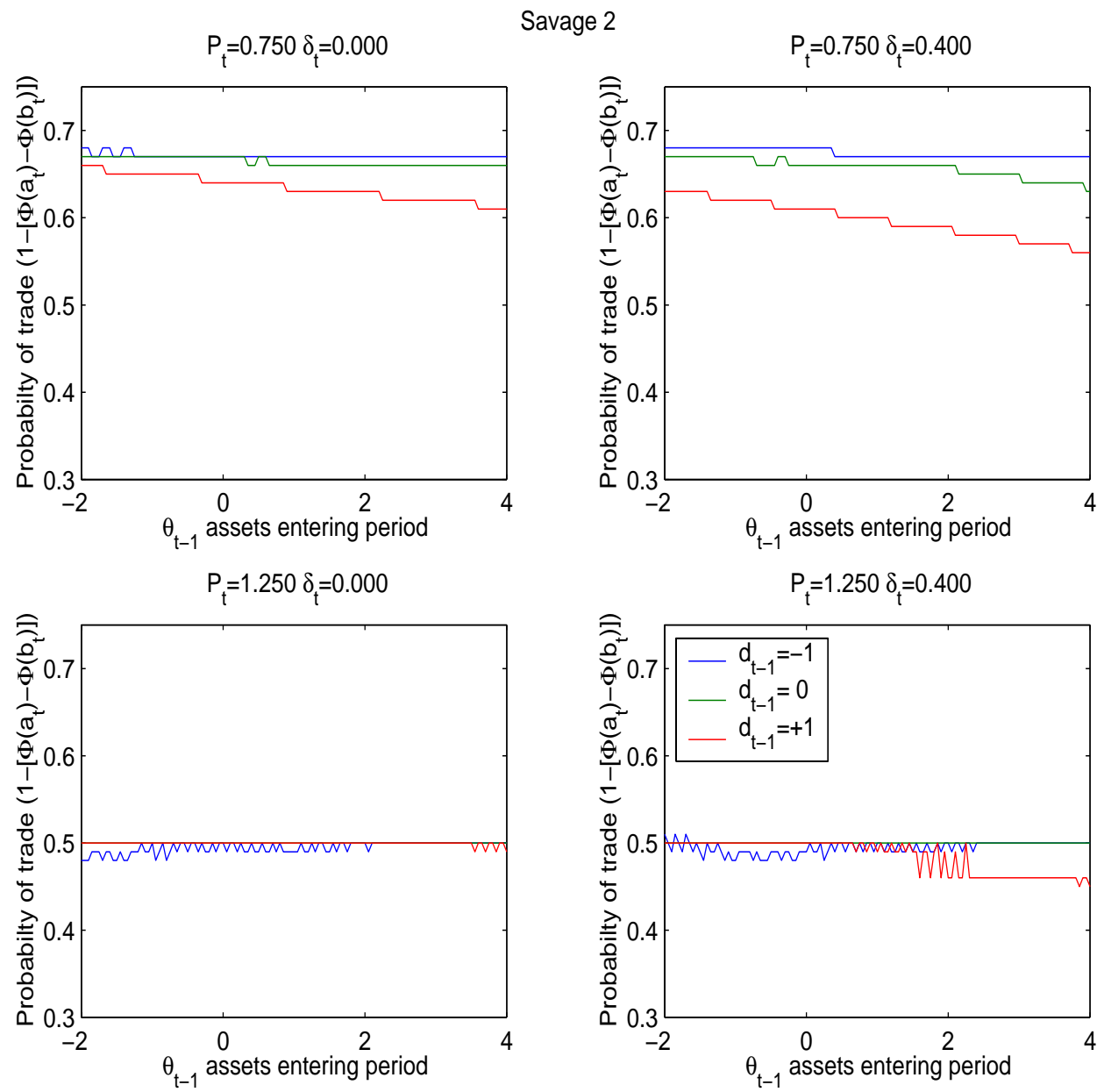

The figure shows the probability of a trade occurring given the bid and ask policy that solves equation (6) for the Savage market-maker with beliefs $\pi^{2}$. The probability of a trade is calculated as $1-\left[\Phi\left(a_{t}\right)-\Phi\left(b_{t}\right)\right]$. The probability of as a function of the state variables: previous position in the derivative, $d_{t-1}$ previous position in the portfolio, $\theta_{t-1}$,current asset price, $P_{t}$, and current asset dividend, $\delta_{t}$. 
Figure 16: Probability of Trade - Knight
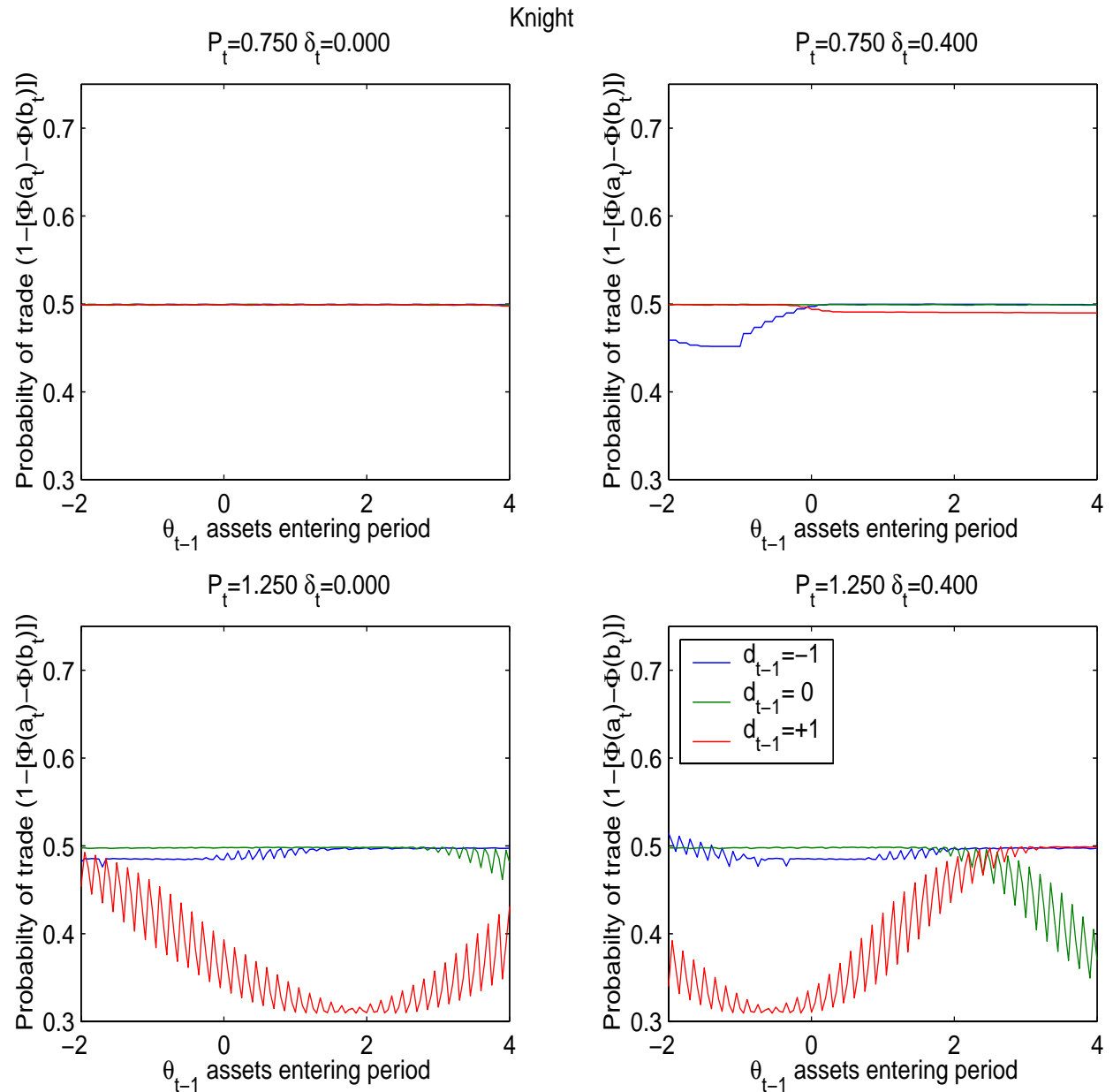

The figure shows the probability of a trade occurring given the bid and ask policy that solves equation (6) for the Knight market maker with uncertainty aversion represented by $\Pi^{K}=\left\{\pi^{1}, \pi^{2}\right\}$. The probability of a trade is calculated as $1-$ $\left[\Phi\left(a_{t}\right)-\Phi\left(b_{t}\right)\right]$. The probability of as a function of the state variables: previous position in the derivative, $d_{t-1}$ previous position in the portfolio, $\theta_{t-1}$, current asset price, $P_{t}$, and current asset dividend, $\delta_{t}$. 
Figure 17: Optimal Portfolio - Knight $\pi^{2}$
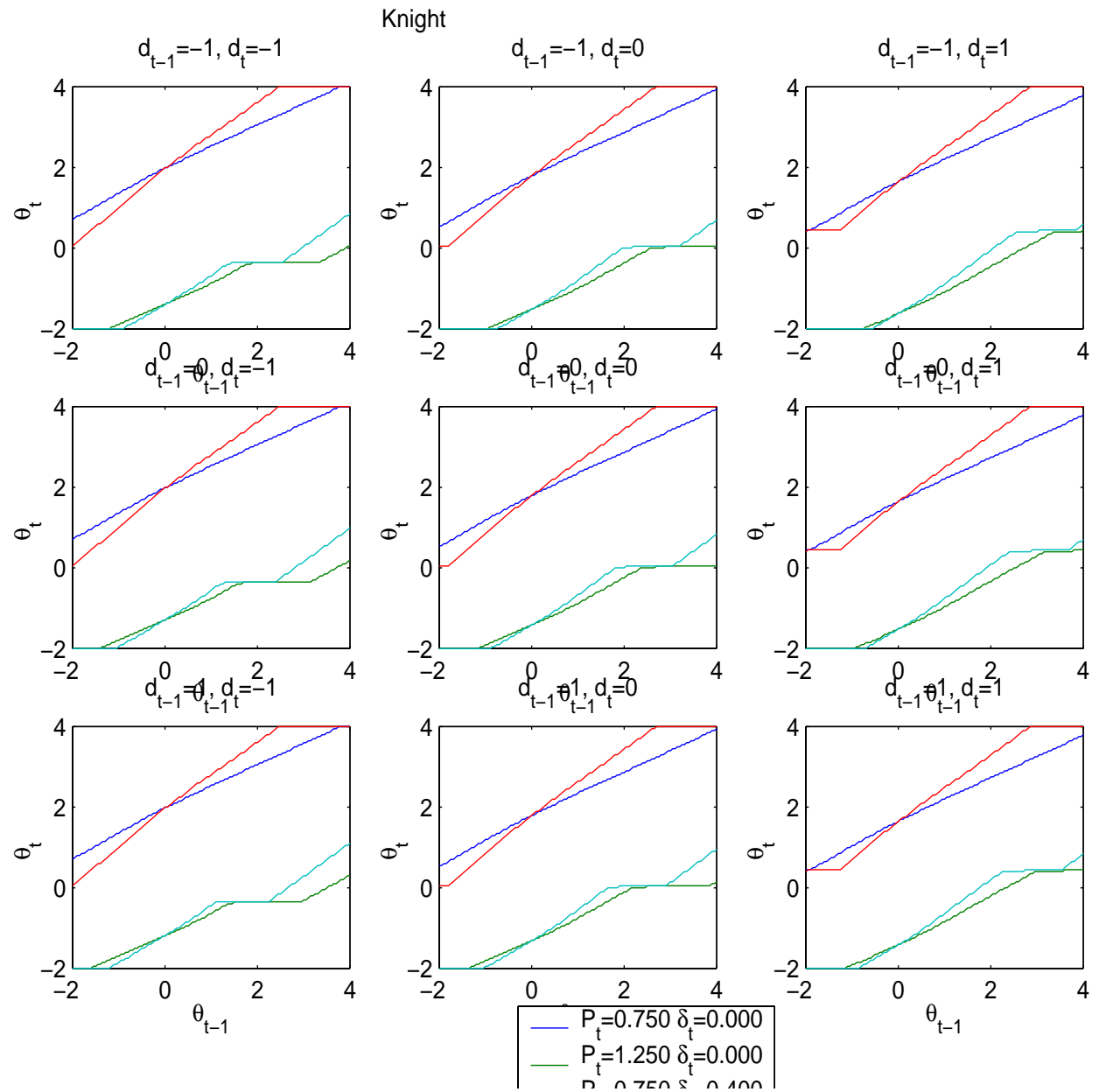

The figure shows the optimal portfolio that solves equation (6) for the Knight market maker with uncertainty aversion represented by $\Pi^{K}=\left\{\pi^{1}, \pi^{2}\right\}$. The optimal portfolio is a function of the state variables: current, $d_{t}$, and previous, $d_{t-1}$ position in the derivative, previous position in the portfolio, $\theta_{t-1}$,current asset price, $P_{t}$, and current asset dividend, $\delta_{t}$. 
probability for derivative trade is low occur, for example, when $P_{t}=1.25$, $\delta_{t}=0, d_{t-1}=1$, and $\theta_{t} \approx 2$ (see lower-left panel of Figure 16). This situation corresponds to the lower three panels of Figure 17 where $d_{t-1}=1$. In particular, the lower two lines. Note that the lack of liquidity is occurring at a point where the portfolio policy function is flat which is where Knightian uncertainty is of first-order importance.

\subsection{Time Series Behavior}

To better understand the implications of these policy functions, it is helpful to simulate realizations for the economy. A simulation consists of drawing a price $P_{t}$, dividend $\delta_{t}$, and willingness to trade, $\tilde{v}_{t}$ and applying the optimal policies for ask and bid prices and the portfolio. The results are for a simulation of 10,000 periods of the economy under both of the possible probability measures, $\pi^{1}$ and $\pi^{2}$, that describe the evolution of prices and dividends.

Figure 18 shows a realized path of bid and ask prices for the three marketmakers. Fifty periods are shown. The two Savage traders differ in their beliefs about the likelihood of next period's price and dividend. The more optimistic Savage market-maker, $\pi^{1}$, tends to have a higher bid and ask price for the derivative. It is not the case that the Knight market-maker simply adopts the worst-case bid and ask. In other words, the derivative is not valued as a standalone investment according to the worst-case distribution. Were this to be the case, the Knight market-maker would adopt the optimistic Savage's ask and the pessimistic Savage's bid. ${ }^{19}$ However, as was discussed in the two-period portfolio choice case, uncertainty aversion manifests in behavior that is more complicated than simply the worst case since the characterization of the worst case can depend on the portfolio choice.

\footnotetext{
${ }^{19}$ If one is considering a long position in a call option, the worst-case distribution has a low mean and low variance for the underlying asset. If one is going short a call, the worst case is a high mean and high variance.
} 
Figure 18: Simulated Bid and Ask Prices
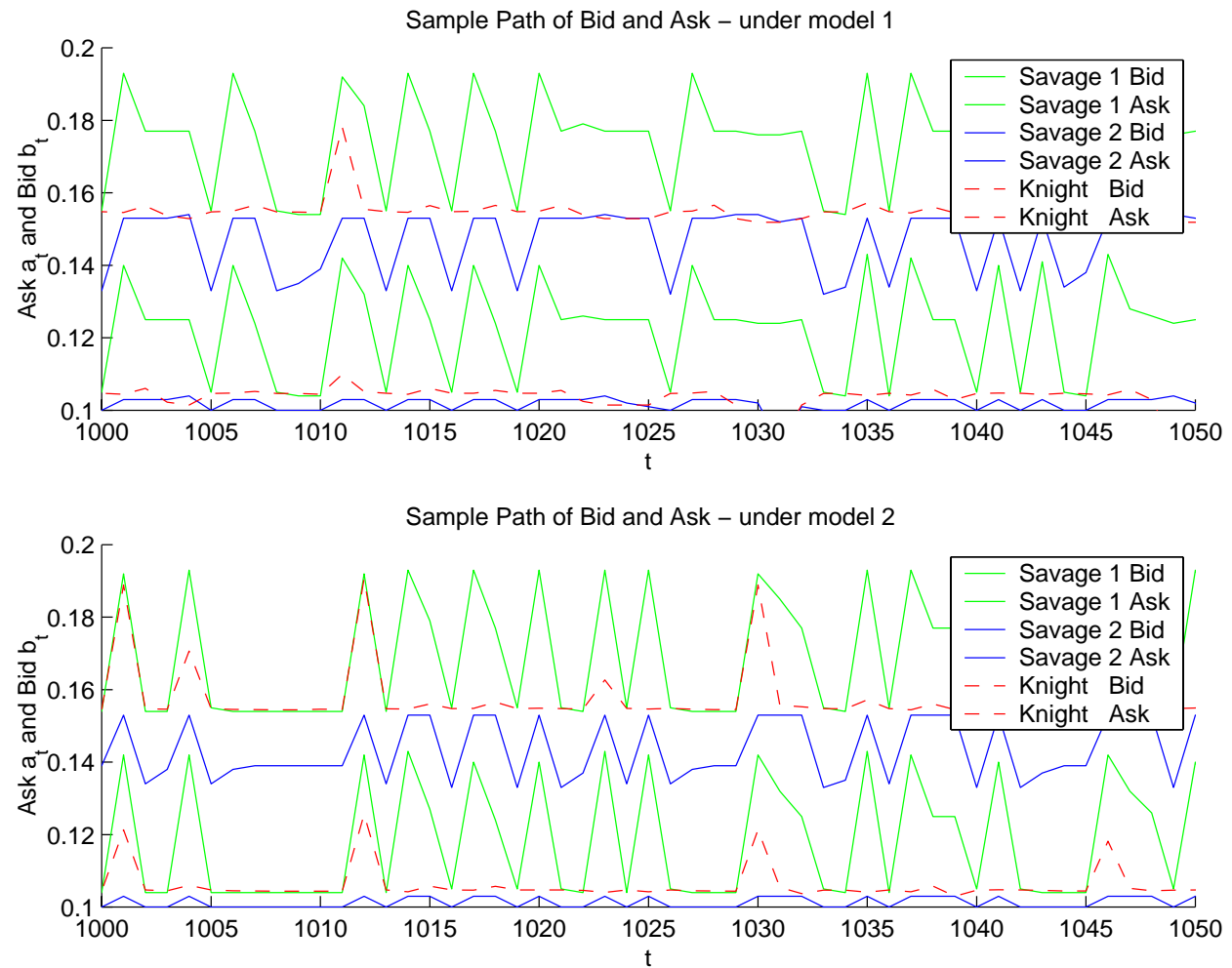

For a simulation of the economy, the optimal realized ask and bid prices are shown for three market-makers: a Savage market maker with beliefs $\pi^{1}$, a Savage with beliefs $\pi^{2}$, and a Knight market maker with uncertainty averse beliefs represented by $\Pi^{K}=\left\{\pi^{1}, \pi^{2}\right\}$. One period of the simulation consists of drawing a price $P_{t}$, dividend $\delta_{t}$, and willingness to trade, $\tilde{v}_{t}$. Of the 10,000 periods simulated, 50 periods are shown. The top panel is simulated under $\pi^{1}$ and the bottom panel is simulated under $\pi^{2}$ (see equation (18) for parameters. 
Relative to the Savage market-makers, the uncertainty aversion of the Knight market-maker produces a less liquid market for the derivative in that the probability of trade is lower. Figure 19 shows the steady-state distribution for the likelihood of trade in any given period (based on a simulation). For all three traders, the median likelihood of trade is close to 0.5. The more optimistic Savage, $\pi^{2}$, has periods of higher liquidity. The Knight market-maker, has slightly lower median trade likelihood. Figure 20 shows the frequency of the position in the derivative. For all three market makers there is a higher frequency of short positions than long. This is specific to the parameterization of the example. As expected, the more pessimistic Savage market-maker, $\pi^{2}$, is less likely to take a long position in the derivative.

For the Knight market-maker, there is a small frequency of very low liquidity realizations. Figure 21 shows a sample path for the time-series of the probability of trade. With the Knight market-maker, the market experiences short, infrequent dips in liquidity where the probability of trade drops dramatically. As discussed previously, this drop in liquidity coincides with the case where uncertainty is of first-order importance and there is no portfoliofree worst-case distribution. In these cases, the portfolio choice of the Knight and the bid-ask behavior are distinct from behavior under either of the Savage traders. In these times of crisis, the Knightian behavior is not representable by a worst-case Savage trader.

In the simulation without any market-making activity shown in Figure 13, the realized path for the optimal portfolio of the Knight trader is bounded by the portfolio position of the two Savage traders. This is not surprising, given this relationship holds state-by-state (see Figure 12). In this setting, the realized path of the state variables $P_{t}$ and $\delta_{t}$ is common across trader types. However, in the case where the trader is also a market maker, the optimal portfolio is not just a function of the exogenous state variables $P_{t}$ and $\delta_{t}$. It also depends on the position in the derivative, $d_{t}$. Since the bid and ask policies of the different market makers differ, the realized path in the derivative need not be common across all market-maker types. It is therefore 
Figure 19: Frequency for Probability of Trade in the Derivative
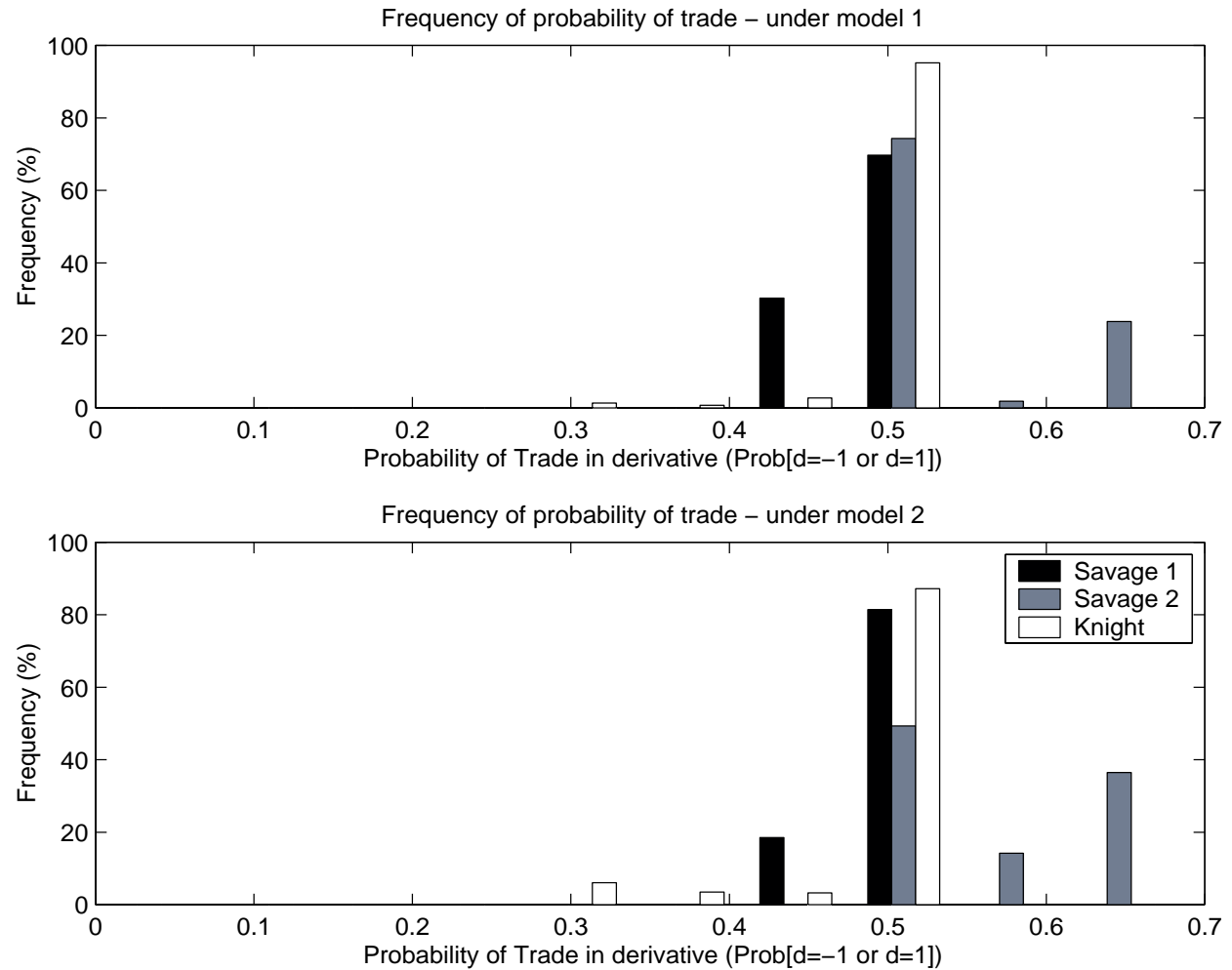

The figure is a histogram of the probability of trade based on 10,000 simulation periods. The probability of a trade is calculated as $1-\left[\Phi\left(a_{t}\right)-\Phi\left(b_{t}\right)\right]$ and depends on the optimal ask and bid prices chosen by the three types of market makers. The three market makers are a Savage market maker with beliefs $\pi^{1}$, a Savage with beliefs $\pi^{2}$, and a Knight market maker with uncertainty averse beliefs represented by $\Pi^{K}=\left\{\pi^{1}, \pi^{2}\right\}$. One period of the simulation consists of drawing a price $P_{t}$ and a dividend $\delta_{t}$ The top panel is simulated under $\pi^{1}$ and the bottom panel is simulated under $\pi^{2}$ (see equation (18) for parameters.) 
Figure 20: Frequency for Probability of Trade in the Derivative
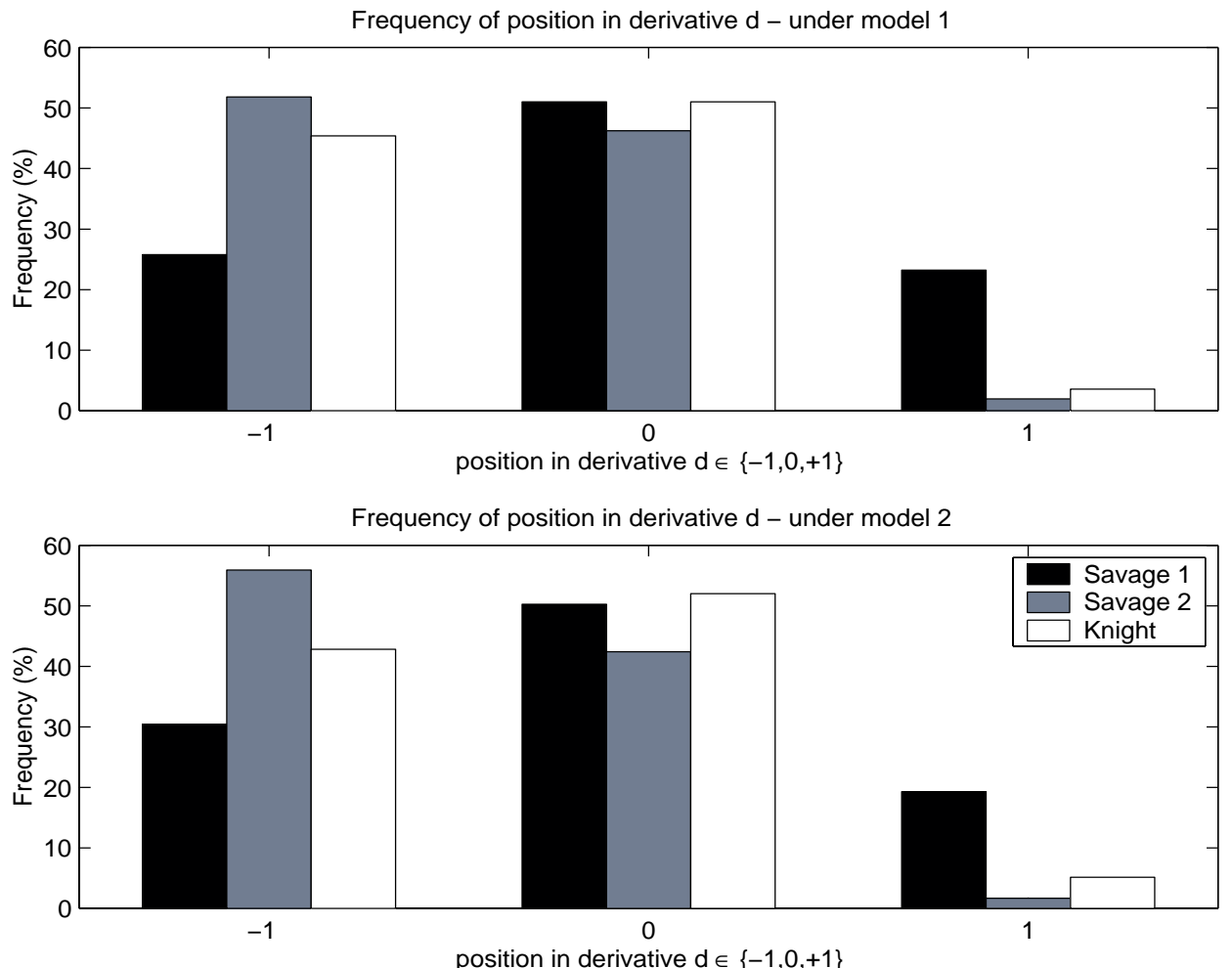

The figure is a histogram of the position in the derivative, $d_{t}$ based on 10,000 simulation periods. The position in the derivative is the outcome of the optimal bid and ask prices the realization of the willingness to trade $\tilde{v}_{t}$. The frequency is shown for a Savage market maker with beliefs $\pi^{1}$, a Savage with beliefs $\pi^{2}$, and a Knight market maker with uncertainty averse beliefs represented by $\Pi^{K}=\left\{\pi^{1}, \pi^{2}\right\}$. One period of the simulation consists of drawing a price $P_{t}$ and a dividend $\delta_{t}$ The top panel is simulated under $\pi^{1}$ and the bottom panel is simulated under $\pi^{2}$ (see equation (18) for parameters.) 
Figure 21: Simulated Probability of Trade in the Derivative

Sample Path of Prob. Trade - under model 1

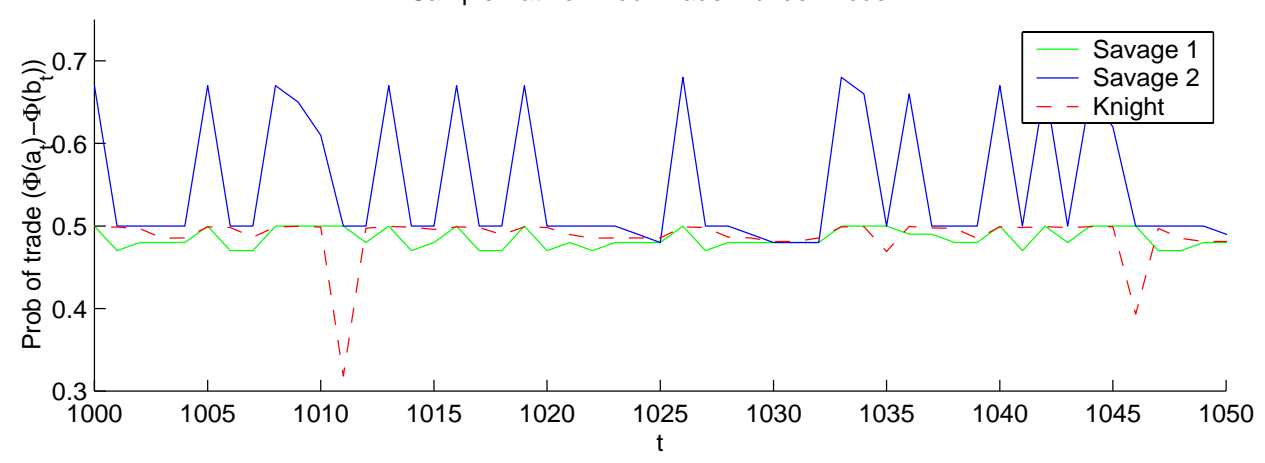

Sample Path of Prob. Trade - under model 2

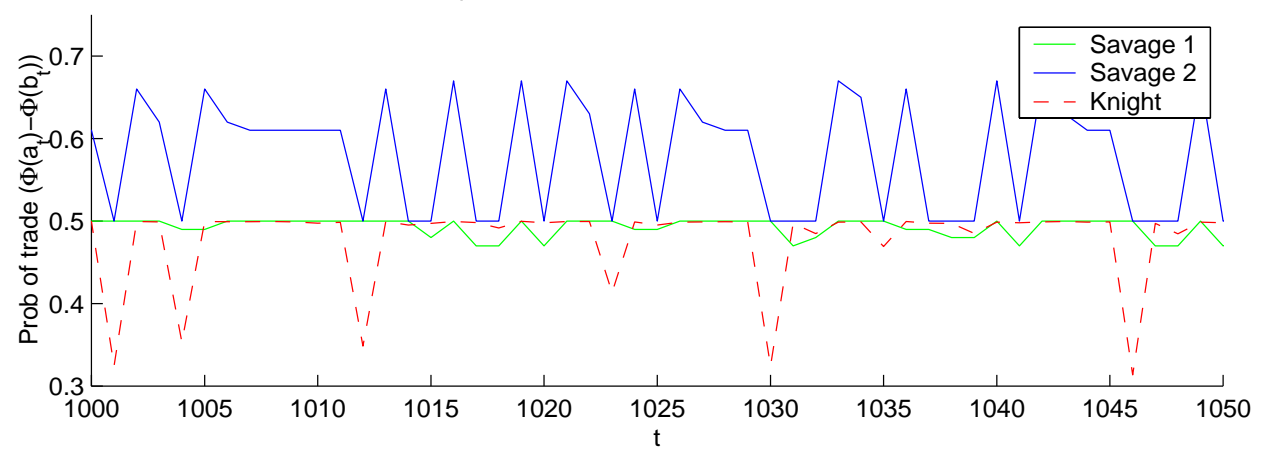

The figure is a realized path for the probability of trade. Of 10,000 simulation periods, a representative 50 periods are shown. The probability of a trade is calculated as $1-\left[\Phi\left(a_{t}\right)-\Phi\left(b_{t}\right)\right]$ and depends on the optimal ask and bid prices chosen by the three types of market makers. The three market makers are a Savage market maker with beliefs $\pi^{1}$, a Savage with beliefs $\pi^{2}$, and a Knight market maker with uncertainty averse beliefs represented by $\Pi^{K}=\left\{\pi^{1}, \pi^{2}\right\}$. One period of the simulation consists of drawing a price $P_{t}$ and a dividend $\delta_{t}$ The top panel is simulated under $\pi^{1}$ and the bottom panel is simulated under $\pi^{2}$ (see equation (18) for parameters.) 
not necessarily the case that the realized portfolio of the Knight market maker be bounded by the Savage portfolio. However, in the simulation, it is the case that $\theta_{t}^{1} \leq \theta_{t}^{K} \leq \theta_{t}^{2}$. This is seen in Figure 22. In this entire simulation, as in the portion shown in the figure, the portfolio of the Knight marketmaker is bounded by the two Savage portfolios. For completeness, we also show the frequency of portfolio holdings in Figure 23. Not surprisingly, the pessimistic Savage market-maker, $\pi^{1}$, typically has lower asset holdings and is more frequently short. The more optimistic market-maker, $\pi^{2}$, is more often long. The distribution for the Knight market-maker lies in between.

\section{Conclusions}

In a simple model of liquidity provision by a monopoly market-maker, an aversion to Knightian uncertainty can significantly reduce liquidity. The marketmaker in our model chooses bid and ask prices for a derivative security to optimally tradeoff the probability of attracting a trade with the current and future income of a particular derivatives position. When there is ambiguity about the appropriate probability distribution for the underlying security's future cash-flows, the market maker is uncertain about the dynamic consequences of their derivatives trading. This uncertainty increases the market-maker's bidask spreads and reduces liquidity. For example, in an infinite-horizon model with a stationary environment, the optimal behavior of the market maker can produce short and dramatic decreases in liquidity in situations where an expected-utility market maker would exhibit no such decrease. Surprisingly, the uncertainty aversion does not produce markets that are always less liquid. Much of the time, the uncertainty aversion manifests itself in the form of the "worst-case" distribution. In these situations, the bid-ask behavior is similar to a Savage market-maker - albeit a Savage with pessimistic beliefs. However, in some situations, the uncertainty is of first-order importance and there is no obvious characterization of the worst-case distribution. In these cases, the Knightian liquidity is much smaller than an otherwise similar Savage 
Figure 22: Simulated Portfolio Holdings
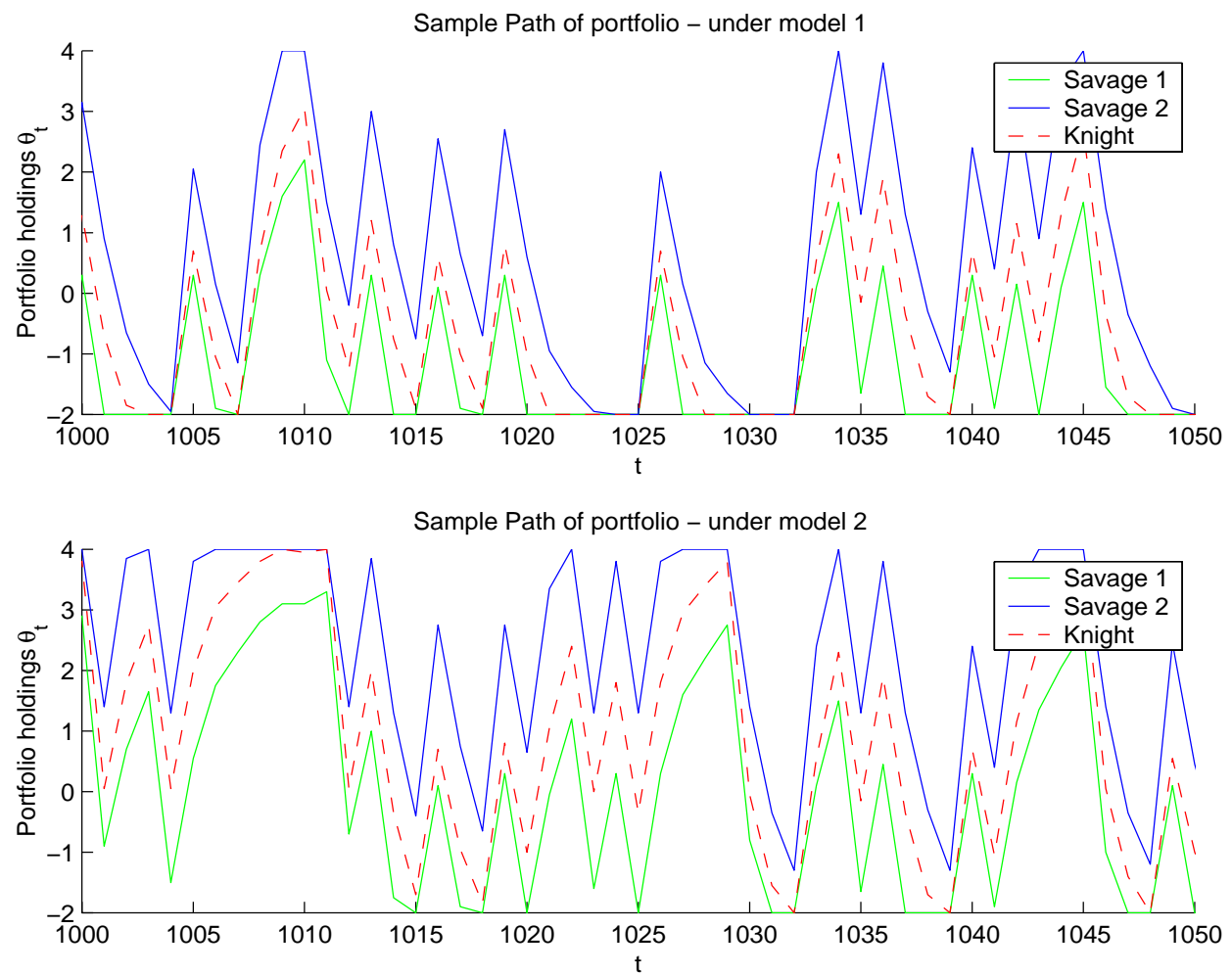

The figure is a realized path for the optimal portfolio. Of 10,000 simulation periods, a representative 50 periods are shown. The portfolio path is shown for three market makers are a Savage market maker with beliefs $\pi^{1}$, a Savage with beliefs $\pi^{2}$, and a Knight market maker with uncertainty averse beliefs represented by $\Pi^{K}=\left\{\pi^{1}, \pi^{2}\right\}$. One period of the simulation consists of drawing a price $P_{t}$ and a dividend $\delta_{t}$ The top panel is simulated under $\pi^{1}$ and the bottom panel is simulated under $\pi^{2}$ (see equation (18) for parameters.) 
Figure 23: Frequency for Portfolio Holdings
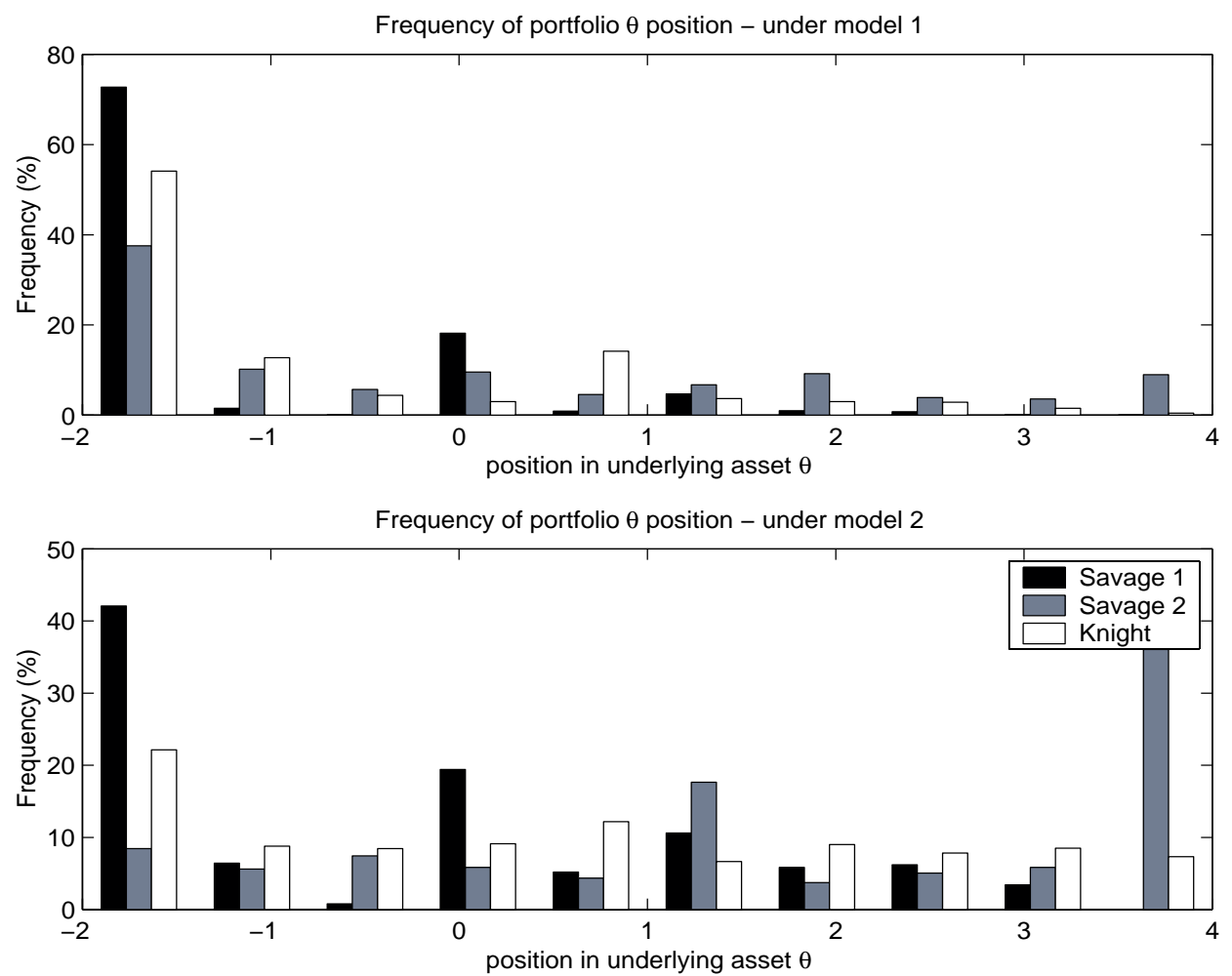

The figure is a histogram of the portfolio in the underlying asset, $\theta_{t}$ based on 10,000 simulation periods. The frequency is shown for a Savage market maker with beliefs $\pi^{1}$, a Savage with beliefs $\pi^{2}$, and a Knight market maker with uncertainty averse beliefs represented by $\Pi^{K}=\left\{\pi^{1}, \pi^{2}\right\}$. One period of the simulation consists of drawing a price $P_{t}$ and a dividend $\delta_{t}$ The top panel is simulated under $\pi^{1}$ and the bottom panel is simulated under $\pi^{2}$ (see equation (18) for parameters.) 
market-maker.

Much of the understanding of the infinite-horizon example is generated from a simple two-period version of the model. By characterizing the optimal bid and ask prices into their effect on trade arrival, current income, and future income, we isolate the effect of Knightian uncertainty. For example, model uncertainty and uncertainty aversion alone are not sufficient to reduce liquidity. Significant liquidity effects require an interaction between uncertainty aversion and the market structure. Non-competitive market-making, relatively large discrete trades, and an aversion to Knightian uncertainty are all necessary to generate liquidity effects that are significantly different from standard Savage expected utility models. Finally, "hedge portfolios" for the market-maker, which are an important component to understanding spreads and liquidity, can look very different from those implied by a model without Knightian uncertainty.

The paper leaves several important questions open to future research. Future work will extend the set of traded securities to explore the connection between uncertainty and liquidity spill-over effects like the "flight to quality" and "contagion." The unusual nature of the hedge portfolio produced by a Knightian uncertain trader suggest that such uncertainty as a natural conduit for contagion. In addition, a model with a larger set of securities will allow us to explore "ambiguity hedging" which can be thought of as a natural counterpart to standard "risk hedging." 


\section{References}

Bank of International Settlements (1999): "A Review of Finanical Market Events in Autumn 1998," Committee on the global financial system, Bank of International Settlements, Basel, Switzerland.

Becker, T., B. Chadha, And A. Sy (2000): "Foreign Exchange Bid-Ask Spreads in the Asian Crisis," Working Paper, International Monetary Fund.

Black, F., and M. Scholes (1973): "The Pricing of Options and Corporate Liabilities," Journal of Political Economy, 81, 637-659.

Choquet, G. (1955): "Theory of Capacities," Annals de l'Institute Forier, $5,131-295$.

Dow, J., And S. Werlang (1992): "Uncertainty Aversion, Risk Aversion, and the Optimal Choice of Portfolio," Econometrica, 60(1), 197-204.

EllsberG, D. (1961): "Risk, Ambiguity,and the Savage axioms," Quarterly Journal of Economics, 75, 643-669.

Epstein, L. G. (2001): "Sharing Ambiguity," American Economic Review: Papers and Proceedings, 91(2), 45-50.

Epstein, L. G., And T. WAng (1994): "Intertemporal Asset Pricing Under Knightian Uncertainty," Econometrica, 62, 283-322.

(1995): "Uncertainty, Risk-Neutral Measures and Security Price Booms and Crashes," Journal of Economic Theory, 67, 40-82.

GilboA, I. (1987): "Expected Utility with Purely Subjective Non-Addative Probabilities," Journal of Mathematical Economics, 16, 65-88.

GilboA, I., AND D. Schmeidler (1989): "Maxmin Expected Utility with Non-Unique Prior," Journal of Mathematical Economics, 18, 141-153.

Grossman, S. J., And M. H. Miller (1988): "Liquidity and Market Structure," Journal of Finance (Papers and Proceedings), 43(3), 617-633.

Hansen, L. P., T. J. Sargent, and T. D. Tallarini (1999): "Robust Permanent Income and Pricing," Review of Economic Studies, 66, 873-907.

Ho, T., ANd H. Stoll (1981): "Opitmal Dealer Pricing Under Transactions and Return Uncertainty," Journal of Financial Economics, 9, 47-73. 
International Monetary Fund (1998): "World Economic Outlook and Intertational Capital Markets: Interim Assessment December 1998," World economic and financial surveys, International Monetary Fund, Washington, DC.

Knight, F. H. (1921): Risk, Uncertainty and Profit. Houghton Mifflin, Boston, MA.

Kyle, A. S. (1985): "Continuous Auctions and Insider Trading," Econometrica, 53, 1315-1335.

Marshall, D. A. (2001): "The Crisis of 1998 and the Role of the Central Bank," Economic Perspectives, Federal Reserve Bank of Chicago, 25(1), 223.

Prati, A., And M. Sbracia (2001): "Currency Crises and Uncertainty About Fundamentals," Working Paper, International Monetary Fund.

Routledge, B. R., M. Trick, And S. E. Zin (2000): "Solution Algorithms for Dynamic Programs with Uncertainty Aversion," Carnegie Mellon University Working Paper.

Savage, L. (1954): The Foundations of Statistics. Wiley, New York, NY.

Schmeidler, D. (1989): "Subjective Probability and Expected Utility without Additivity," Econometrica, 57(3), 571-587.

Scholes, M. S. (2000): "Crisis and Risk Management," American Economic Review - Papers and Proceedings, 90(2), 17-21.

Seidenfeld, T., and L. Wasserman (1993): "Dilation for Sets of Probabilities," Annals of Statistics, 21(3), 1139-1154.

Summers, L. H. (2000): "International Financial Crises: Causes, Prevention, and Cures," American Economic Review - Papers and Proceedings, 90(2), 1-17. 